\title{
Current Trends in MXene-Based Nanomaterials for Energy Storage and Conversion System: A Mini Review
}

\author{
Karthik Kannan ${ }^{1}$, Kishor Kumar Sadasivuni ${ }^{1, *}$, Aboubakr M. Abdullah ${ }^{1}$ and Bijandra Kumar ${ }^{2, *}$ \\ 1 Center for Advanced Materials, Qatar University, P.O. Box 2713, Doha, Qatar; \\ karthik.kannan@qu.edu.qa (K.K.); bakr@qu.edu.qa (A.M.A.) \\ 2 Department of Technology, Elizabeth City State University, Elizabeth City, NC 27909, USA \\ * Correspondence: kishorkumars@qu.edu.qa (K.K.S.); bkumar@ecsu.edu (B.K.)
}

Received: 9 March 2020; Accepted: 14 April 2020; Published: 1 May 2020

\begin{abstract}
MXene is deemed to be one of the best attentive materials in an extensive range of applications due to its stupendous optical, electronic, thermal, and mechanical properties. Several MXene-based nanomaterials with extraordinary characteristics have been proposed, prepared, and practiced as a catalyst due to its two-dimensional (2D) structure, large specific surface area, facile decoration, and high adsorption capacity. This review summarizes the synthesis and characterization studies, and the appropriate applications in the catalysis field, exclusively in the energy storage systems. Ultimately, we also discussed the encounters and prospects for the future growth of MXene-based nanomaterials as an efficient candidate in developing efficient energy storage systems. This review delivers crucial knowledge within the scientific community intending to design efficient energy storage systems.
\end{abstract}

Keywords: MXene; 2D materials; Li-ion batteries; supercapacitors; Proton reduction; $\mathrm{CO}_{2}$ conversion and oxygen reduction

\section{Introduction}

Two-dimensional layered materials have substantial research due to their amazing structural [1-3], mechanical [4], electronic [5,6], and optical properties [7]. Apart from graphene, transition metals dichalcogenides (TMDs), phosphorene, and their derivatives are illustrations of the extreme examined $2 \mathrm{D}$ materials. The finding of $2 \mathrm{D}$-layered titanium carbide powder $\left(\mathrm{Ti}_{3} \mathrm{C}_{2}\right)$, the first candidate of the MXene family, in 2011 has unique structural and electronic features, permitting their usage on numerous possible applications [8,9].

MXenes are the latest group of 2D transition metal carbides, carbonitrides, and nitrides. The MXenes $\left(\mathrm{M}_{\mathrm{n}+1} \mathrm{X}_{\mathrm{n}} \mathrm{T}_{\mathrm{x}}\right.$, whereas $\mathrm{M}$ refers to $\mathrm{Sc}, \mathrm{V}, \mathrm{Cr}, \mathrm{Ti}, \mathrm{Zr}, \mathrm{Mo}, \mathrm{Nb}, \mathrm{Hf}, \mathrm{Ta}$; $\mathrm{X}$ refers to nitrogen or carbon, and $\mathrm{T}$ refers to $-\mathrm{OH},-\mathrm{O}$, and $-\mathrm{F})$ can be prepared by selective etching of ( $\mathrm{Al}, \mathrm{Cd}, \mathrm{Si}, \mathrm{P}$, $\mathrm{S}, \mathrm{Ga}, \mathrm{As}, \mathrm{Ge}, \mathrm{In}, \mathrm{Sn}, \mathrm{Ti}, \mathrm{Pb}$ elements) layers from three-fold metal nitrides and carbides (MAX phase). Usually, $M_{n+1} A X_{n}$ (MAX) phases are the starting compounds, and MXenes are formed by specifically etching the A layers, where A denotes $\mathrm{Al}$ or Si (Figure 1). Major properties have since been reported, such as graphene-like layered structure, hydrophilicity, electrical conductivity, and flexibility. Nearly 30 combinations of materials have been previously produced, and so many were projected hypothetically $[10,11]$.

MXenes have been broadly studied for their applications in numerous fields; for example, MXenes have been researched as new materials for Li-ion batteries (LIBs), electrodes, supercapacitors, hydrogen storage, adsorption, and catalysts [12,13]. In this review, we systematically present the techniques to synthesize MXene-based catalysts, followed by crucial comments and probable solutions. We then concisely reviewed the investigation methods that were related to applications in the catalysis field and solely in the energy storage and conversion systems [14-20]. Also, the structure and stability of 
MXenes are discussed concentrating on the morphological, optical, and electronic properties followed by some of the utmost favorable applications, such as batteries, proton reduction, supercapacitors, $\mathrm{CO}_{2}$ conversion, and oxygen reduction. At last, a lookout for forthcoming research is suggested from the recent research confronts. Also, we assume that the upcoming research employs this study as a particular direction to relate, examine, and enlarge MXenes acquaintance. Recently, MXene based nanomaterials have emerged as a popular trend towards potential applications such as LIBs, supercapacitor, sensing, and biosensing. Therefore, a mini-review is provided to the materials science community, as an intense, quick, and significant indication on the investigational progress of MXenes research, signifying their present status, challenges, and trends.

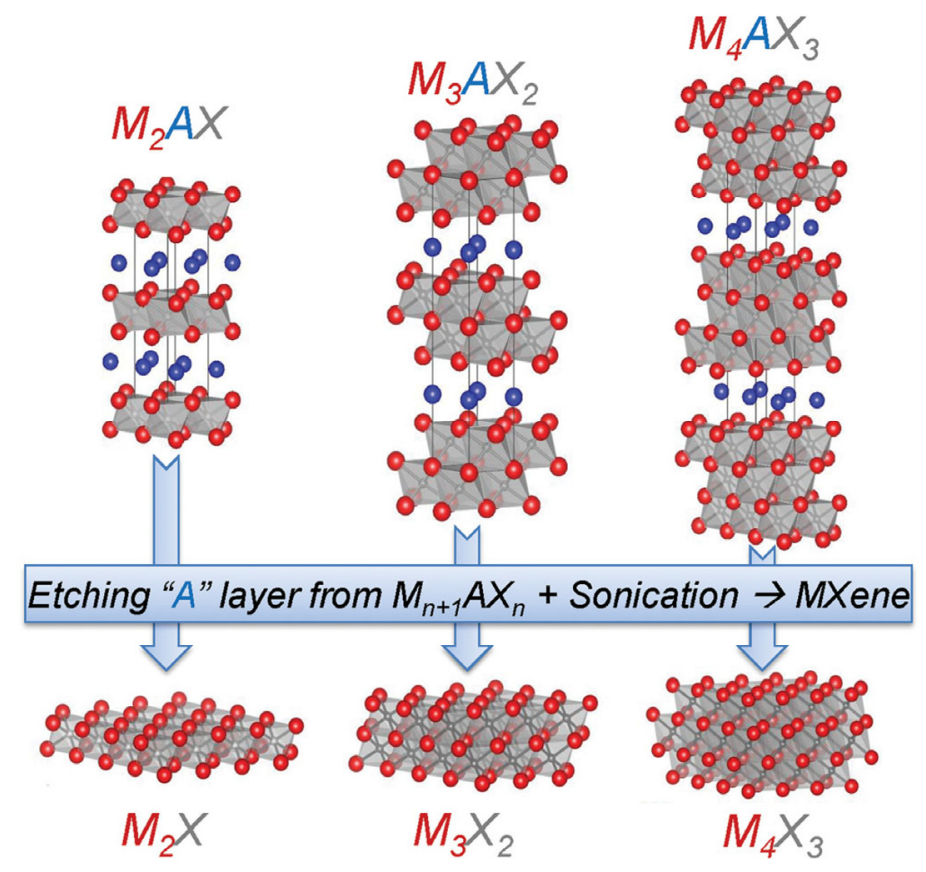

Figure 1. Structures of typical $\mathrm{M}_{2} \mathrm{AX}, \mathrm{M}_{3} \mathrm{AX}{ }_{2}, \mathrm{M}_{4} \mathrm{AX}$ 3 phases. Reprinted with permission from [8].

\section{Synthesis and Characterization of MXenes}

\subsection{Synthesis}

\subsubsection{Synthesis Method}

The MAX phase (under the inert gas flowing or solid in a vacuum) has been synthesized via pressureless sintering (PLS) method (low-cost). Commonly MAX phase (without any pressure aid through sintering route) was prepared by this method as hot isostatic pressing (HIP) and hot press (HP) [21]. The approach of exfoliation is applied to preparation MXene from the MAX phase (discriminant etching layers of A-group elements in the MAX phase by an HF solution as the etchant) [22]. Another general method-vacuum filtration-is used to fabricate thin films of MXene materials. Initially, MXene materials are dispersed. Then, a vacuum pump is utilized to suck the diffusion to go via a filter. After solvent-passing via the filter, the film or membrane created of MXene materials will form [23].

One-or few-layer MXene nanosheets, which preserves the crystal structure and properties obtained via exfoliation method. Next, the adaptability and low cost of this method make it highly well-liked for synthesizing MXene materials and tremendously suitable for original research. MXene materials are produced by ball-milling with the assistance of liquid surfactants or solid exfoliation agents, as ball-milling of materials (bulk precursor) regularly manufactures nanosized particles owing to high-energy collisions [24]. 
In this liquid-phase impregnation method, the loading solution is mixed with the mesoporous material, and then the solvent is evaporated. The incipient wetness impregnation method refers to impregnation using a solution with a volume equal to the pore volume of the materials [25].

Chemical Vapor Deposition (CVD) is a procedure in which the substrate is exposed to one or more unpredictable precursors, which respond and decay on the substrate surface to create the needed thin film deposition [26]. Spark plasma sintering (SPS) is a new technique that uses pressure-driven powder consolidation in which a pulsed direct electric current passes via a sample squeezed in a graphite matrix. It is too identified as field-assisted or pulse electric current sintering [27].

Transition metal atoms into a perovskite (host) lattice throughout the preparation in oxidizing atmospheres, and the surface as nanosized metallic particles under reducing conditions have been prepared by in-situ growth [28]. Deposits of one monolayer of metal carbide (MXene) onto an mTMDC (monolayer transition metal dichalcogenide), and to subsequently oxidize the top-layer metal atoms was approached by atomic layer deposition (ALD) [29].

Diverse MXenes can be constructed by Acid etching (HF etching) at room temperature to different temperatures by regulating the concentration of $\mathrm{HF}$ and reaction time. HF is a wildly discriminating etchant that is still competent in removing various polytypes of $\mathrm{SiC}$. The etching is a kinetically inhibited development, and each MXene wants a dissimilar etching time to attain an entire conversion. Regularly MXenes with larger $n$ in $M_{n+1} C_{n} T_{x}$ needs sturdy etching and/or a longer etching time [30,31].

\subsubsection{MXene Preparation}

The MXene sheets consisting of Al-containing MAX phases can be synthesized using hydrofluoric acid (HF) as an etching solution. For instance, $\mathrm{Ti}_{3} \mathrm{AlC}_{2}(2.0 \mathrm{~g})$ was gradually added to $40 \mathrm{~mL}$ of $40 \%$ $\mathrm{HF}$ solutions and the reaction mixture was mixed using a stirrer at $60^{\circ} \mathrm{C}$ for $18 \mathrm{~h}$. The solids in the solution were gathered by centrifuging, washed with double distilled water, and lyophilized. During the synthesis, the subsequent reaction mechanism was followed:

$$
\begin{gathered}
\mathrm{Ti}_{3} \mathrm{AlC}_{2}+3 \mathrm{HF} \rightarrow \mathrm{Ti}_{3} \mathrm{C}_{2}+\mathrm{AlF}_{3}+3 / 2 \mathrm{H}_{2} \\
\mathrm{Ti}_{3} \mathrm{C}_{2}+2 \mathrm{H}_{2} \mathrm{O} \rightarrow \mathrm{Ti}_{3} \mathrm{C}_{2}(\mathrm{OH})_{2}+\mathrm{H}_{2} \\
\mathrm{Ti}_{3} \mathrm{C}_{2}+2 \mathrm{HF} \rightarrow \mathrm{Ti}_{3} \mathrm{C}_{2} \mathrm{~F}_{2}+\mathrm{H}_{2}
\end{gathered}
$$

The etching conditions (HF concentration and time) that were necessary to change a given MAX phase differ extensively, depending on the temperature and particle size. For example, decreasing the particle size of the MAX phase by ball milling can efficiently reduce the essential etching time and the strength of HF [32,33]. Besides, divergences in M-Al bond energies for dissimilar MAX phases also need different etching conditions. For instance, the greater Ti-Al bond energy in $\mathrm{Ti}_{2} \mathrm{AlC}$ likened with the $\mathrm{Nb}-\mathrm{Al}$ bond energy in $\mathrm{Nb}_{2} \mathrm{AlC}$ leads to an increased $\mathrm{HF}$ concentration and extended etching time [34]. Therefore, suitable etching conditions are required to accomplish greater yields and finish the exchange of Mxenes from MAX phases. Recently, Halim et al. projected the usage of ammonium bifluoride $\left(\mathrm{NH}_{4} \mathrm{HF}_{2}\right)$ as an etchant in place of the harmful $\mathrm{HF}$ [35].

Ghidiu et al. described the latest greater-yield process for the prompt synthesis of numerous MXene sheets [36]. Herein, they prepared $\mathrm{Ti}_{3} \mathrm{C}_{2} \mathrm{~T} x$ by dissolving $\mathrm{Ti}_{3} \mathrm{AlC}_{2}$ powders in hydrogen chloride $(\mathrm{HCl})$ and lithium fluoride $(\mathrm{LiF})$ solutions, and then heated the mixture for $45 \mathrm{~h}$ at $40{ }^{\circ} \mathrm{C}$. Afterward, the product was collected by washing the sediments thoroughly to eliminate the side products and increased the $\mathrm{pH}$. Moreover, various $\mathrm{Ti}_{2} \mathrm{CT}_{\mathrm{x}}$ morphologies were achieved via using specific surfactants (i.e., centyltrimethylammonium bromide (CTAB), dodecyltrimethylammonium bromide (DTAB), tetradecyltrimethylammonium bromide (TTAB), stearyltrimethylammonium bromide (STAB), dioctadecyldimethlylammonium chloride (DDAC)), and intercalating agents (i.e., p-phosphonic calix[n]arenes) throughout the ultrasonication step. In this process, the ring size of the surfactant controlled the morphology of MXene (crumpled sheets, plates, spheres, and scrolls, correspondingly 
with $\mathrm{n}=4,5,6$, or 8). The preparation and separation of ultrathin $2 \mathrm{D} \mathrm{Ti}_{3} \mathrm{C}_{2}$ nanosheets were attained by a liquid exfoliation process blending HF etching and tetrapropylammonium hydroxide (TPAOH) insertion [16].

Though many investigates are insisting on getting a well-regulated morphology, lateral sizes, architecture, and also a termination group production procedure, other methods were used for MXene nanocomposite preparation. For instance, $\mathrm{Mn}_{3} \mathrm{O}_{4}$ nanoparticles sustained on layered $\mathrm{Ti}_{3} \mathrm{C}_{2} \mathrm{MXene}$ $\left(\mathrm{Mn}_{3} \mathrm{O}_{4} / \mathrm{MXene}\right.$ nanocomposite) have been prepared by the ultra-sonication method [37]. Hierarchical $\mathrm{Ti}_{3} \mathrm{C}_{2} \mathrm{QDs} / \mathrm{Cu}_{2} \mathrm{O}$ nanowires/Cu heterostructures were prepared via a simple self-assembly strategy [38]. Arranging g- $\mathrm{C}_{3} \mathrm{~N}_{4}$ nanosheets with $\mathrm{Ti}_{3} \mathrm{C}_{2}$ MXene nanocomposites were synthesized via the interface electrostatic interaction method [39]. Construct $\mathrm{MXene} / \mathrm{CuO}$ nanocomposite was prepared by the thermal decomposition method [40]. The multiwall carbon nanotubes (MWCNTs) patterned with $\mathrm{MoS}_{2}$ quantum dots ( $\left.\mathrm{MoS}_{2} \mathrm{QDs}\right)$, and $\mathrm{Ti}_{3} \mathrm{C}_{2} \mathrm{~T}_{x}$ QDs (MoS2QDs@Ti3C2T $x$ QDs@MWCNTs) were prepared by the hydrothermal method [41].

MXene $\mathrm{Ti}_{3} \mathrm{C}_{2}$ nanosheets were synthesized via hot-pressed sintering technique using concentrate $\mathrm{HF}$ solution with various calcination temperatures $\left(400,600\right.$, and $\left.800^{\circ} \mathrm{C}\right)$ [21]. Mo-based MXenes were fabricated by vacuum-assisted filtration method [23]. Michael et al. have fabricated titanium carbide MXene via the hydrothermal method. MXene nanosheets terminated with different functional groups using post-processing techniques [42]. Ling et al. have prepared MXene with polymer [Polydiallyidimethyl ammonium chloride (PDDA), polyvinyl alcohol (PVA)] composites using the HF etching method [31]. MXene/graphene oxide fiber was prepared by a liquid crystal assisted fiber spinning technique [43]. MXene/rGO fibers have prepared via the wet-spinning assembly method [44]. Synthesis of $\mathrm{Ti}_{3} \mathrm{C}_{2} \mathrm{~T}_{\mathrm{x}}$ MXene via ball milling has reported by Ghidhu et al. [38]. Li et al. have demonstrated the MXene with electrochemically exfoliated graphene by solution processing method [45].

\subsection{Characterization}

The XRD pattern of prepared MXene, which are well-matched with the characteristic structure of synthesized $\mathrm{Ti}_{3} \mathrm{C}_{2}$ MXene. Supplementary peaks were observed in the $\mathrm{Mn}_{3} \mathrm{O}_{4} / \mathrm{MXene}$ XRD pattern, implying $\mathrm{Mn}_{3} \mathrm{O}_{4}$ particles are formed on MXene [46]. The XRD pattern displays the fabrication of $\mathrm{Ti}_{3} \mathrm{AlC}_{2} \mathrm{MAX}$ phase. The intensity of the peaks originated from the parent $\mathrm{Ti}_{3} \mathrm{AlC}_{2}$ bulk consecutively reduced after $\mathrm{HF}$ etching and TPAOH intercalation [47]. Heterostructures with $\mathrm{Ti}_{3} \mathrm{C}_{2}$ QDs or $\mathrm{Ti}_{3} \mathrm{C}_{2}$ sheets related peaks (Figure 2a) represent an amorphous carbon signal nearby $24^{\circ}$ [48]. $\mathrm{Ti}_{3} \mathrm{C}_{2}$ nanoparticles

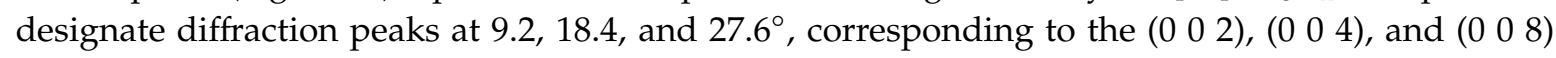
reflections, correspondingly. Additionally, the transformation of $\mathrm{Ti}_{3} \mathrm{AlC}_{2}$ to $\mathrm{Ti}_{3} \mathrm{C}_{2}$ nanoparticles is further affirmed by the vanishing of the sturdiest peak of diffraction at $39.2^{\circ}$ of $\mathrm{Ti}_{3} \mathrm{AlC}_{2}$ and the lower shift of the (0 04 ) peaks [49]. Diffraction peaks matching to both $\mathrm{MXene}$ and $\mathrm{CuO}$ were viewed in the pattern of $\mathrm{MXene} / \mathrm{CuO}$ nanocomposite (Figure $2 \mathrm{~b}$ ), and the peak intensity increased with the increased content of $\mathrm{CuO}$, demonstrating the fabrication of the $\mathrm{MXene} / \mathrm{CuO}$ composite [50]. The clear peak at $2 \theta$ of $26.2^{\circ}$ in the XRD pattern of the Ti3C2T $x$ QDs resembles the restacking of graphene layers [51]. The stretching vibration at 3400,725 , and $1050 \mathrm{~cm}^{-1}$ were allocated to be $\mathrm{O}-\mathrm{H}, \mathrm{C}=\mathrm{O}$, and $\mathrm{C}-\mathrm{O}$. The detected $\mathrm{OH}$ groups reveal the high hydrophilic property of $\mathrm{MXene}$ and $\mathrm{Mn}_{3} \mathrm{O}_{4} / \mathrm{MXene}$. The structure of MXene reveals by the vibration peak of Ti-O bond appeared at $665 \mathrm{~cm}^{-1}$ [46]. Fourier transform infrared (FTIR) spectra, where the peaks at 1629.2, 1028.6, and $561.4 \mathrm{~cm}^{-1}$ relate to the modes of stretching vibration for $\mathrm{C}=\mathrm{O}, \mathrm{C}-\mathrm{F}$, and Ti-O groups grafted onto $\mathrm{Ti}_{3} \mathrm{C}_{2}$ during synthesis (Figure $2 \mathrm{c}$ ). Raman spectra of $\mathrm{Ti}_{3} \mathrm{AlC}_{2}$ and $\mathrm{Ti}_{3} \mathrm{C}_{2}$ nanosheets, the disappearance of the vibration modes $\omega_{2}, \omega_{3}$, and $\omega_{4}$ due to treatment with $\mathrm{HF}$ indicates the elimination of the $\mathrm{Al}$ layer or the interchange of the $\mathrm{Al}$ atoms with additional atoms. Mode $\omega_{5}$ has downshifted and worsened, whereas the mode $\omega_{6}$ has been mixed and repressed, which designates the well-preserved $\mathrm{Ti}_{3} \mathrm{C}_{2}$ layer and the increment of interlayer spacing for the structure of MXene [47]. Self-assembly of $\mathrm{Ti}_{3} \mathrm{C}_{2}$ samples on $\mathrm{Cu}_{2} \mathrm{O} \mathrm{NWs} / \mathrm{Cu}$ is demonstrated by Raman signals at 1383 and $1612 \mathrm{~cm}^{-1}$ that are in agreement with the $\mathrm{D}$ and $\mathrm{G}$ bands of $\mathrm{Ti}_{3} \mathrm{C}_{2}$ samples 
(Figure 2d) [48]. XPS result for the nanosheets of $\mathrm{Ti}_{3} \mathrm{C}_{2}$ reveals the existence of $\mathrm{Ti}$ (IV), $\mathrm{TiC}_{x} \mathrm{O}_{y}$, and intrinsic Ti-C bond, which designates the growth of $\mathrm{TiO}_{2}$ or $\mathrm{Ti}_{3} \mathrm{C}_{2}(\mathrm{OH})_{2}$ [47]. Successful fabrication of $\mathrm{Cu}_{2} \mathrm{O}$ NWs$/ \mathrm{Cu}$ mesh, $\mathrm{Ti}_{3} \mathrm{C}_{2}$ sheets $/ \mathrm{Cu}_{2} \mathrm{O}$ NWs $/ \mathrm{Cu}$, and $\mathrm{Ti}_{3} \mathrm{C}_{2} \mathrm{QDs} / \mathrm{Cu}_{2} \mathrm{O}$ NWs$/ \mathrm{Cu}$ heterostructures is also validated by the presence of $\mathrm{Cu} 2 p$, Ti 2p, and $\mathrm{C} 1$ s peaks in the high-resolution XPS [48]. The Ti 2p spectrum displayed in Figure 2e is intricated into six components incorporating the peaks at 461.3 and $455.0 \mathrm{eV}$ assigned to Ti-C $2 \mathrm{p}_{1 / 2}$ and Ti-C $2 \mathrm{p}_{3 / 2}$ and also the peaks at 464.7 and $459.1 \mathrm{eV}$ assigned to Ti-O $2 \mathrm{p}_{1 / 2}$ and Ti-O $2 \mathrm{p}_{3 / 2}$, correspondingly. The peaks at 462.5 and $456.5 \mathrm{eV}$ are attributed to $\mathrm{Ti}-\mathrm{X}\left(\mathrm{Ti}^{2+}\right)$, which resembles the sub-stoichiometric TiC or titanium oxycarbides [49]. The presence of C-Ti bonds at $282.2 \mathrm{eV}$ in the high-resolution spectra of $\mathrm{C} 1 \mathrm{~s}$ demonstrated the retained structure of MXene after hybridization with $\mathrm{CuO}$. The two main binding energy peaks at 932.7 and $952.6 \mathrm{eV}$ with the splitting peak of $19.9 \mathrm{eV}$ in the high-resolution spectrum of $\mathrm{Cu} 2 \mathrm{p}$ could be ascribed to $\mathrm{Cu} 2 \mathrm{p}_{3 / 2}$ and $\mathrm{Cu} 2 \mathrm{p}_{1 / 2}$, consistently. Moreover, there are also the satellite peaks at 944.2 and $962.6 \mathrm{eV}$ which later corroborated the presence of Copper oxide. The peaks at 284.0 and $285.0 \mathrm{eV}$ also communicate to $\mathrm{C}-\mathrm{C} / \mathrm{C}=\mathrm{C}$ and $\mathrm{C}-\mathrm{O}$, collected with the peak at 285.8 and 287.8, which are assigned to the $\mathrm{C}-\mathrm{OH}$ and $\mathrm{COOH}$ groups (Figure 2f) [50-52].
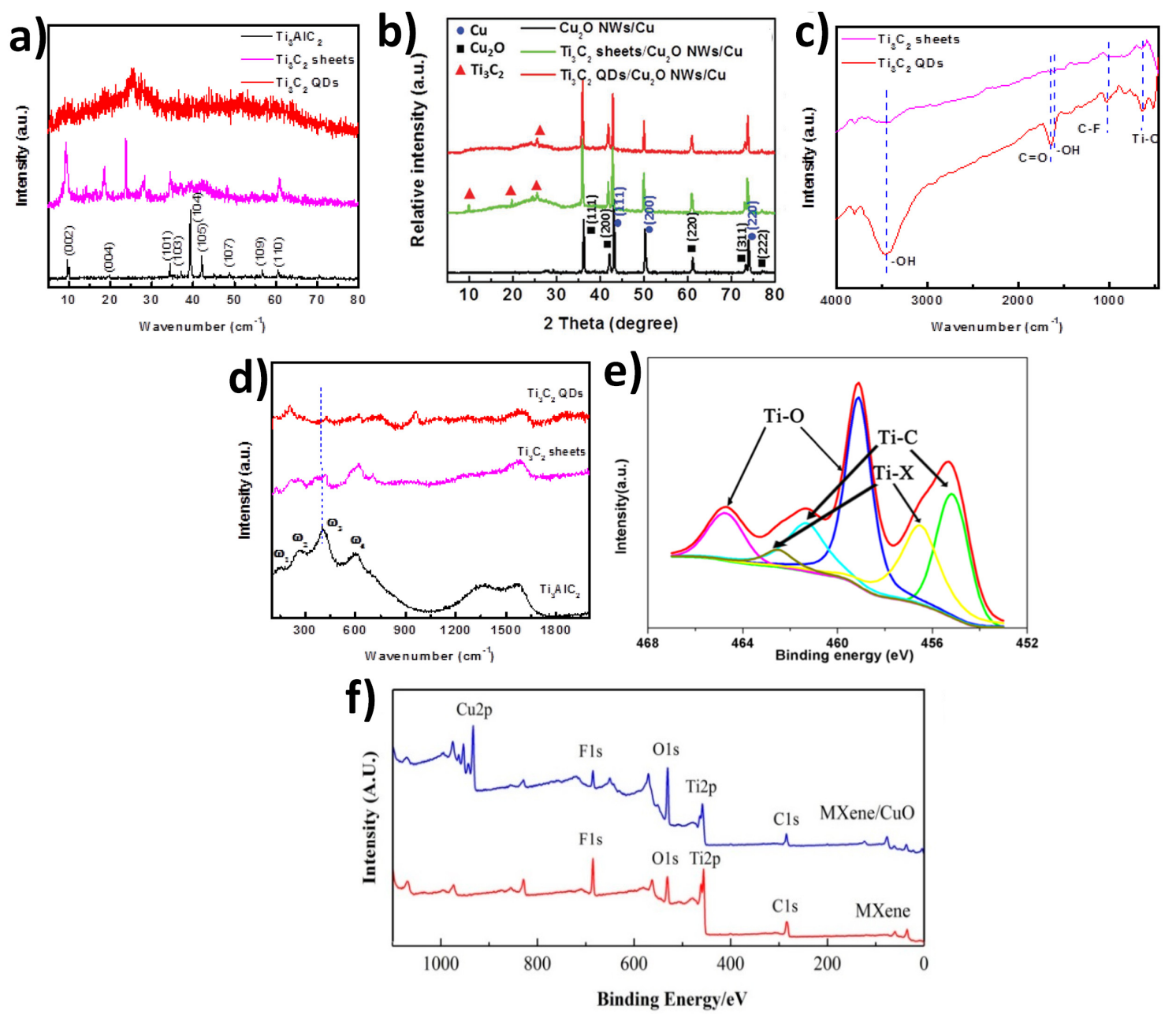

Figure 2. (a,b) XRD pattern of MXene sheets and QDs, MXene/CuO nanocomposite, (c) FTIR spectrum of MXene sheets and QDs, (d) Raman spectrum of MXene sheets and QDs and (e,f) XPS spectra of MXene with $\mathrm{C}_{3} \mathrm{~N}_{4}, \mathrm{MXene} / \mathrm{CuO}$. Reprinted with permission from $[48,50,52]$. 


\section{Fundamental Properties of MXene with Relevance in Energy Storage System}

\subsection{Electronic and Electrical Properties}

Electronic and electrical properties are in the center of energy storage systems. The electrical and electronic properties of MXene can be tailored by modification of functional groups, solid-solution configuration, or stoichiometry. According to scientific methods, electric conductivity values of MXenes pressed discs were identical with multi-layered graphene (resistance values from $22 \Omega$ to $339 \Omega$, relying on the " $\mathrm{n}$ " index and its molecular formula), and were greater compared to $0.1 \mathrm{mg} / \mathrm{mL}$ CNTs (Carbon nanotubes) and $1 \mathrm{wt} \%$ RGO (Reduced graphene oxide) materials $[8,14]$. It has also been noticed that the resistance of MXenes highly depends on the number of layers and type of functional group. It increases with a higher number of layers [34,53-56].

Table 1 summarizes the electrical conductivity of numerous MXenes and composites prepared by different methods. It has been observed that the electrical conductivity of $\mathrm{Ti}_{3} \mathrm{C}_{2} \mathrm{~T}_{\mathrm{x}}$ differed from 850

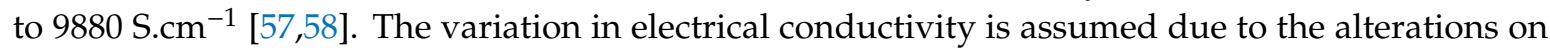
the (i) surface functional groups, (ii) defect concentration, (iii) delamination yield, (iv) lateral sizes, and (v) d-spacing between MXenes flakes provoked by each method of etching. Generally, poor concentrations of HF and shorter etching times produce MXenes with reduced imperfections and larger lateral sizes, rendering greater electrical conductivities. Surrounding environments, mainly humidity, might also affect their conductivities, facing in the direction of applications of comparative humidity sensing material [59-61]. Surface modification is an important tool to enhance the electrical properties of MXenes via thermal and alkaline processes. In particular, surface modification processes result, in addition or part of functional groups (specifically-F), and intercalating molecules. Many details about electronic structures of MXenes and correlated features are reported in a current review work of Hantanasirisakul et al. [62].

Table 1. Summary of the various MXene nanocomposites with the method of synthesis for electrical conductivity.

\begin{tabular}{|c|c|c|c|}
\hline Sample & Method of Synthesis & Electrical Conductivity $(\mathrm{S} / \mathrm{cm})$ & Ref. \\
\hline $\mathrm{Ti}_{3} \mathrm{C}_{2}$ & \multirow{3}{*}{ Hot press sintering } & 850 & [21] \\
\hline $\mathrm{Ti}_{3} \mathrm{C}_{2} @ 400{ }^{\circ} \mathrm{C}$ & & 1430 & {$[21]$} \\
\hline $\mathrm{Ti}_{3} \mathrm{C}_{2} @ 600^{\circ} \mathrm{C}$ & & 2410 & [21] \\
\hline $\mathrm{Mo}_{2} \mathrm{CT}_{\mathrm{x}}$ & \multirow{4}{*}{$\begin{array}{l}\text { Vacuum-assisted } \\
\text { filtration method }\end{array}$} & 1.2 & {$[23]$} \\
\hline$\left(\mathrm{Mo}_{2} \mathrm{Ti}\right) \mathrm{C}_{2} \mathrm{~T}_{\mathrm{x}}$ & & 1494 & [23] \\
\hline$\left(\mathrm{Mo}_{2} \mathrm{Ti}_{2}\right) \mathrm{C}_{3} \mathrm{~T}_{\mathrm{x}}$ & & 614 & {$[63]$} \\
\hline $\mathrm{Ti}_{3} \mathrm{C}_{2} \mathrm{~T}_{\mathrm{x}}$ & & 2410 & {$[63]$} \\
\hline $\mathrm{Ti}_{3} \mathrm{C}_{2} \mathrm{~T}_{\mathrm{x}}(100 \%)$ & \multirow{4}{*}{ Hydrothermal } & 4556 & {$[64]$} \\
\hline 99\% MXene/1\% rGO & & 3326 & {$[64]$} \\
\hline 95\% MXene/5\% rGO & & 2261 & [65] \\
\hline $90 \%$ MXene $/ 10 \%$ rGO & & 1231 & [65] \\
\hline
\end{tabular}

From Table 1, MXene based composites by hydrothermal method show good electrical properties (electrical conductivity, resistivity, etc.) and also highly useful in many applications such as sensors and screens.

\subsection{Morphological Properties}

The lattice parameter of surface-functionalized $\mathrm{Ti}_{3} \mathrm{C}_{2}$ increases after insertion and delamination. Nevertheless, their work was separated MXenes layers of 20-50 nm thickness and length 44-90 $\mu \mathrm{m}$. 
Additionally, soon after ultrasonication in DMSO, these MXenes were scattered in deionized water to develop an aqueous solution with colloidal property, later filtered to get MXene "paper" [53].

In another study, $\mathrm{Ti}_{3} \mathrm{C}_{2}$ Quantum Dots (QDs)/ $\mathrm{Cu}_{2} \mathrm{O}$ NWs composites were prepared. Coating by $\mathrm{Ti}_{3} \mathrm{C}_{2}$ QDs does not modify the complete morphology of $\mathrm{Cu}_{2} \mathrm{O}$ NWs but shields the porous surfaces (Figure 3). Effective deposition of $\mathrm{Ti}_{3} \mathrm{C}_{2}$ QDs was also established by elemental mapping. Transmission Electron Microscopy (TEM) and High-Resolution Transmission Electron Microscopy (HRTEM) morphological analysis confirmed that plentiful $\mathrm{Ti}_{3} \mathrm{C}_{2}$ QDs were consistently immobilized on $\mathrm{Cu}_{2} \mathrm{O}$ NWs with close contact. It was also proved by the identical spreading of $\mathrm{C}, \mathrm{Ti}, \mathrm{Cu}$, and $\mathrm{O}$ elements disclosed by elemental mapping [48].

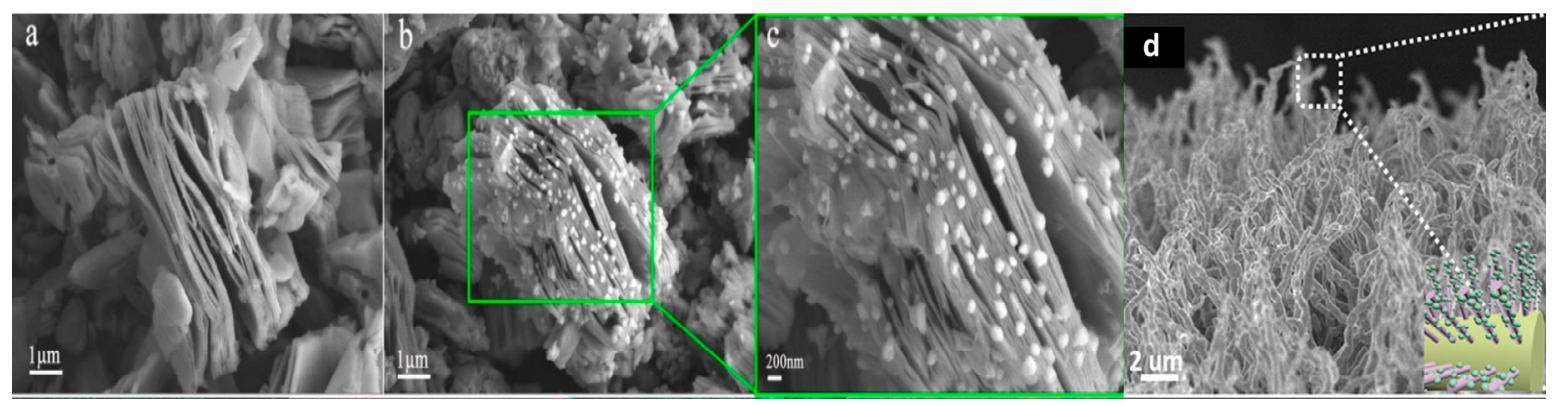

Figure 3. (a,b) Morphology of MXene/50\% CuO nanocomposite, (c) MXene/50\% CuO nanocomposite and $(\mathbf{d}) \mathrm{Ti}_{3} \mathrm{C}_{2} / \mathrm{Cu}_{2} \mathrm{O}$ (magnification: $200 \mathrm{~nm}$ ). Reprinted with permission from [48,50].

The SEM images of $\mathrm{MoS}_{2} \mathrm{QDs} @ \mathrm{Ti}_{3} \mathrm{C}_{2} \mathrm{~T}_{x} \mathrm{QDs} @ M W C N T s-2$ nanocomposite only displays nanotube-like structure, in which the $\mathrm{Ti}_{3} \mathrm{C}_{2} \mathrm{~T}_{x}$ QDs and $\mathrm{MoS}_{2}$ QDs were not noticed, retaining to their ultra-small sizes. In turn, its precise surface structure, the TEM images of $\mathrm{MoS}_{2}$ QDs, $\mathrm{Ti}_{3} \mathrm{C}_{2} \mathrm{~T}_{x}$ QDs, and $\mathrm{MoS}_{2} \mathrm{QDs} @ \mathrm{Ti}_{3} \mathrm{C}_{2} \mathrm{~T}_{x} \mathrm{QDs} @ \mathrm{MWCNTs}-2$ were probed [51]. $\mathrm{Mn}_{3} \mathrm{O}_{4}$ nanoparticles on the surface of MXene were investigated by TEM and HRTEM. TEM image evidenced the presence of $\mathrm{Mn}_{3} \mathrm{O}_{4}$ nanoparticles with a diameter of 5-18 nm. The HRTEM image of $\mathrm{Mn}_{3} \mathrm{O}_{4} / \mathrm{MXene}$ displayed the Lattice fringes with inter-planar distances of $0.307 \mathrm{~nm}$, which was allocated to be $\left(\begin{array}{lll}1 & 1 & 2\end{array}\right)$ plane of hausmannite. The inter-planar distance of $0.242 \mathrm{~nm}$ resembles the $\left(\begin{array}{lll}1 & 0 & 3\end{array}\right)$ plane of MXene [46]. The MXene sheets are layered structures that are even and soft with pointed edges, while $\mathrm{Gd}^{3+}$ - and $\mathrm{Sn}^{4+}$-multi doped bismuth ferrite (BFO) nanocomposites are enclosed on the surface of MXene sheets [65]. In the case of MXene quantum dots with cuprous oxide nanowire $\left(\mathrm{Ti}_{3} \mathrm{C}_{2} / \mathrm{Cu}_{2} \mathrm{ONWs} / \mathrm{Cu}\right)$ nanocomposite, $\mathrm{Cu}_{2} \mathrm{O}$ nanowires cover the MXene porous surfaces (Figure 3d) [44]. MXene $/ 50 \% \mathrm{CuO}$ (Figure 3a-c) showed $\mathrm{CuO}$ nanoparticles with 60-100 nm diameters, which were randomly deposited on the surface of MXene nanosheets (Figure 3c), and were stabilized through van der Walls interactions [50].

\subsection{Optical Properties}

The UV and visible light absorptions are essential for the development of photocatalytic, optoelectronic, photovoltaic, and transparent conductive electrode devices. MXenes are possible compounds for adaptable, transparent electrode studies, whereas their greater reflectivity in the UV range directs towards anti-ultraviolet emissions coating materials, because of their transparent optical property in the visible range and electrical conductivity. $\mathrm{Ti}_{3} \mathrm{C}_{2} \mathrm{~T}_{\mathrm{x}}$ films can absorb light in the range of UV-visible between 300 to $500 \mathrm{~nm}$. The transmittance of the $\mathrm{Ti}_{3} \mathrm{C}_{2} \mathrm{~T}_{\mathrm{x}}$ films varied concerning the thickness, and the $5 \mathrm{~nm}$ thick film displayed transmittance up to $91 \%$ (Figure $4 \mathrm{a}$ ). It has been suggested that there might be a presence of a strong and wide absorption band at approximately $700-800 \mathrm{~nm}$, based on the thickness of the film (Figure $4 \mathrm{~b}-\mathrm{c}$ ). It results in the pale green color and is essential for photothermal therapy (PTT) investigations. Remarkably, the transmittance properties can be improved via varying the film thickness and intercalation of ions. For example, while urea, hydrazine, and DMSO decrease $\mathrm{Ti}_{3} \mathrm{C}_{2} \mathrm{~T}_{\mathrm{x}}$ film transmittance, tetramethylammonium hydroxide $\left(\mathrm{NMe}_{4} \mathrm{OH}\right)$ increases it from 74.9 to $92.0 \%$ (Figure 4 d) [66-69]. 

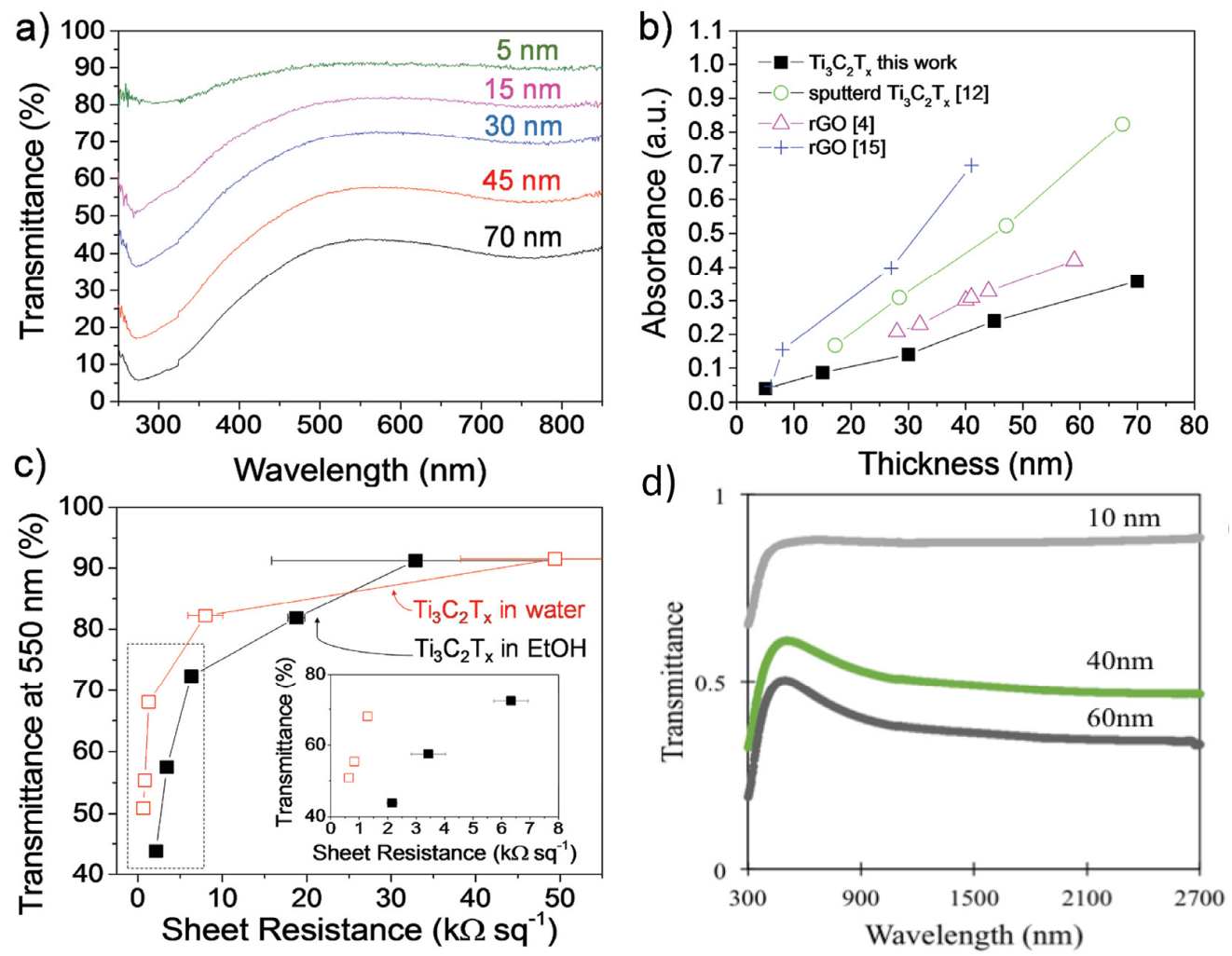

Figure 4. (a) UV-visible spectra of $\mathrm{Ti}_{3} \mathrm{C}_{2} \mathrm{~T}_{x}$ films with various thicknesses, (b) Effect of thickness on the absorbance of $\mathrm{Ti}_{3} \mathrm{C}_{2} \mathrm{~T}_{x}$ films likened with other materials, (c) Sheet resistance against transmittance at $550 \mathrm{~nm}$ of $\mathrm{Ti}_{3} \mathrm{C}_{2} \mathrm{~T}_{x}$ sprayed from ethanol and water solutions and (d) UV-vis-NIR transmittance spectra of spin cast $\mathrm{V}_{2} \mathrm{CT}_{\mathrm{x}}$ films as a function of $13 \mathrm{~h}$ from $10 \mathrm{~nm}$ to $60 \mathrm{~nm}$. Reprinted with permission from $[66,67]$.

The existence of the functional groups also affects the optical properties of 2D components, as was pointed out by the first principle simulations. The hydroxyl and fluorinated terminations represent identical characteristics, compared with oxygen species. For example, in the visible region, $-\mathrm{F}$ and $-\mathrm{OH}$ terminations reduce the reflectivity and absorption, whereas, in the UV range, all the terminations improve the reflectivity when likened with the pristine MXene. It has been signified that weak absorbance is accomplished with the decrement of MXene flake size. Ultimately, it has signified that the excellent light-to-heat conversion efficiency $(\sim 100 \%)$, is beneficial for water evaporation and biomedical treatments. However, certain optical associated characteristics, such as emission colors, luminescence efficiency, plasmonic, and non-linear optical characteristics, are quiet essential to be explained in turn to expand the uses of MXenes [70,71].

\section{MXene for Energy Storage and Conversion Systems}

\subsection{MXene for Energy Storage: Batteries}

Rechargeable lithium-ion batteries (LIBs) are extensively employed as energy storage devices. The best LIB holds a good cyclability, high lithium storage capacity, and elevated rate capacity, all of which rely on the characteristics of the electrode materials existing in LIB's. Graphite is the very frequently employed anode component, but it undergoes problems from a low specific capacity of $372 \mathrm{mAh} / \mathrm{g}$ and deficient rate capability [72,73]. Broad investigation attempts have opened the growth of novel anode materials in LIBs substituted by 2D MXenes [74,75].

Soon after their immediate finding, the probability of employing MXenes as anode materials in LIB was reported [76]. The hypothetical Lithium storage capacity of $\mathrm{Ti}_{3} \mathrm{C}_{2}$ (in the form of $\mathrm{Ti}_{3} \mathrm{C}_{2} \mathrm{Li}_{2}$ ) was $320 \mathrm{mAh} / \mathrm{g}$, related to that of graphite $372 \mathrm{mAh} / \mathrm{g}$. Also, the projected diffusion barrier $(0.07 \mathrm{eV})$ 
for Lithium on bare $\mathrm{Ti}_{3} \mathrm{C}_{2}$ was less compared to graphite $(0.3 \mathrm{eV})$, which expected outstanding high-rate performance for simple MXene [77]. Yet, as noticed beyond, all synthesized MXene sheets are terminated with surface groups, probably worsening their functioning by stimulated steric hindrance. Contrasted with some additional terminated MXene sheets, an O-terminated MXene was recommended to retain very good capacitance [78-80].

The higher capacities of MXene based LIBs were ascribed to (i) enhanced electrolyte ions approachability and diffusion routes to MXene layers; (ii) greater charge storage because of their delaminating layers; (iii) metal hybridization with greater capacitance and outstanding conductivity; (iv) speedier ion diffusion; and (v) lesser interfacial charge transfer [81]. For instance, new structured MXenes-CNTs associations and porous $\mathrm{Ti}_{3} \mathrm{C}_{2} \mathrm{~T}_{\mathrm{X}}$ formed by freeze-drying postponed MXenes re-loading and gave rise to very good properties in comparison to $\mathrm{MoS}_{2}$ /graphene nanocomposites (Figure 5a-c) [82,83]. This should be emphasized that MXenes could also be infused by some additional metal ions like $\mathrm{Na}^{+}, \mathrm{K}^{+}, \mathrm{Al}^{3+}$, and $\mathrm{Mg}^{2+}$. Therefore, they could be employed in non-LIBs; those have their usage recently restricted by suitable electrode properties [79]. $\mathrm{Ti}_{2} \mathrm{C}$ hypothetical capacities for $\mathrm{Mg}^{2+}$ and $\mathrm{Al}^{3+}$ were amongst all the uppermost ever projected for both kinds of ion batteries (687 $\mathrm{mAhg}^{-1}$ and $992 \mathrm{mAhg}^{-1}$ correspondingly) (Figure 5d-e) [84]. Moreover, the probability of sodium ions multilayer adsorptions entices with more attention. Current literature also reveals assuring characteristics as including conductive materials in Li-S type of batteries. It is a promising battery system that gives hypothetical energy densities up to $1675 \mathrm{mAhg}^{-1}$ (Figure 5f) [85], but is restricted by their quick capacity degradation because of polysulfide moving and dissolution, greater enlargement of volume and worse electrical conductivity of sulfur related cathodes $[22,25,86,87]$. Therefore, MXene's growth could head to novel routes on the electrode materials of NLiBs. From Table 2, the MXene with metal oxide composite exhibited high reversible capacity and rate capability due to the enhanced conductivity and contribution of the capacitive capacity.

Table 2. Overview of electrochemical characteristics from MXene and MXene-based composite for batteries.

\begin{tabular}{cccccc}
\hline Materials & Method of Synthesis & $\begin{array}{c}\text { Reversible Capacity } \\
\left(\mathbf{m A h g}^{-1}\right)\end{array}$ & $\begin{array}{c}\text { Rate Capability } \\
\left(\mathbf{m A h g}^{-1}\right)\end{array}$ & Cycles & Ref \\
\hline $\mathrm{Ti}_{2} \mathrm{CT}_{\mathrm{x}}$ & Exfoliation & 225 & 70 & 200 & {$[22]$} \\
\hline $\mathrm{Ti}_{2} \mathrm{C} / \mathrm{TiO}_{2}$ & Chemical exfoliation & 389 & 280 & 1000 & {$[24]$} \\
\hline $\mathrm{Ti}_{3} \mathrm{C}_{2} / \mathrm{CNF}$ & Liquid-phase impregnation & 320 & 97 & 2900 & {$[25]$} \\
\hline $\mathrm{Ti}_{3} \mathrm{C}_{2} \mathrm{~T}_{\mathrm{x}} / \mathrm{CNT}$ & Chemical vapor deposition & 1250 & 500 & 100 & {$[26]$} \\
\hline $\mathrm{Nb}_{4} \mathrm{C}_{3} \mathrm{~T}_{\mathrm{x}}$ & Spark plasma sintering & 380 & 320 & 1000 & {$[27]$} \\
\hline $\mathrm{Ti}_{3} \mathrm{C}_{2} \mathrm{~T}_{\mathrm{x}} / \mathrm{NiCo}_{2} \mathrm{O}_{4}$ & In-situ growth & 1330 & 1200 & 100 & {$[28]$} \\
\hline $\mathrm{SnO}_{2} / \mathrm{Ti}_{3} \mathrm{C}_{2} \mathrm{~T}_{\mathrm{x}}$ & Atomic layer deposition & 1041 & 451 & 50 & {$[29]$} \\
\hline $\mathrm{MoS}_{2} @ \mathrm{Ti}_{3} \mathrm{C}_{2} \mathrm{~T}_{\mathrm{x}}$ & Acid etching & 843 & 132 & 200 & {$[30]$} \\
\hline $\mathrm{V}_{2} \mathrm{CT}_{\mathrm{x}}$ & Ball-milling & 288 & 110 & 150 & {$[86]$} \\
\hline $\mathrm{Nb}_{2} \mathrm{CT}_{\mathrm{x}}$ & Ball-milling & 250 & 370 & 100 & {$[88]$} \\
\hline $\mathrm{Nb}_{2} \mathrm{CT}_{\mathrm{x}} / \mathrm{CNT}$ & Amine-assisted delamination process & 420 & 544 & 200 & {$[89]$} \\
\hline $\mathrm{Sn}(\mathrm{IV}) @ \mathrm{Ti}_{3} \mathrm{C}_{2}$ & Facile liquid-phase immersion process & 635 & 260 & 5000 & {$[90]$} \\
\hline $\mathrm{Ti}_{3} \mathrm{C}_{2} \mathrm{~T}_{\mathrm{x}} / \mathrm{Ag}$ & Direct reduction & 310 & & 150 \\
\hline
\end{tabular}



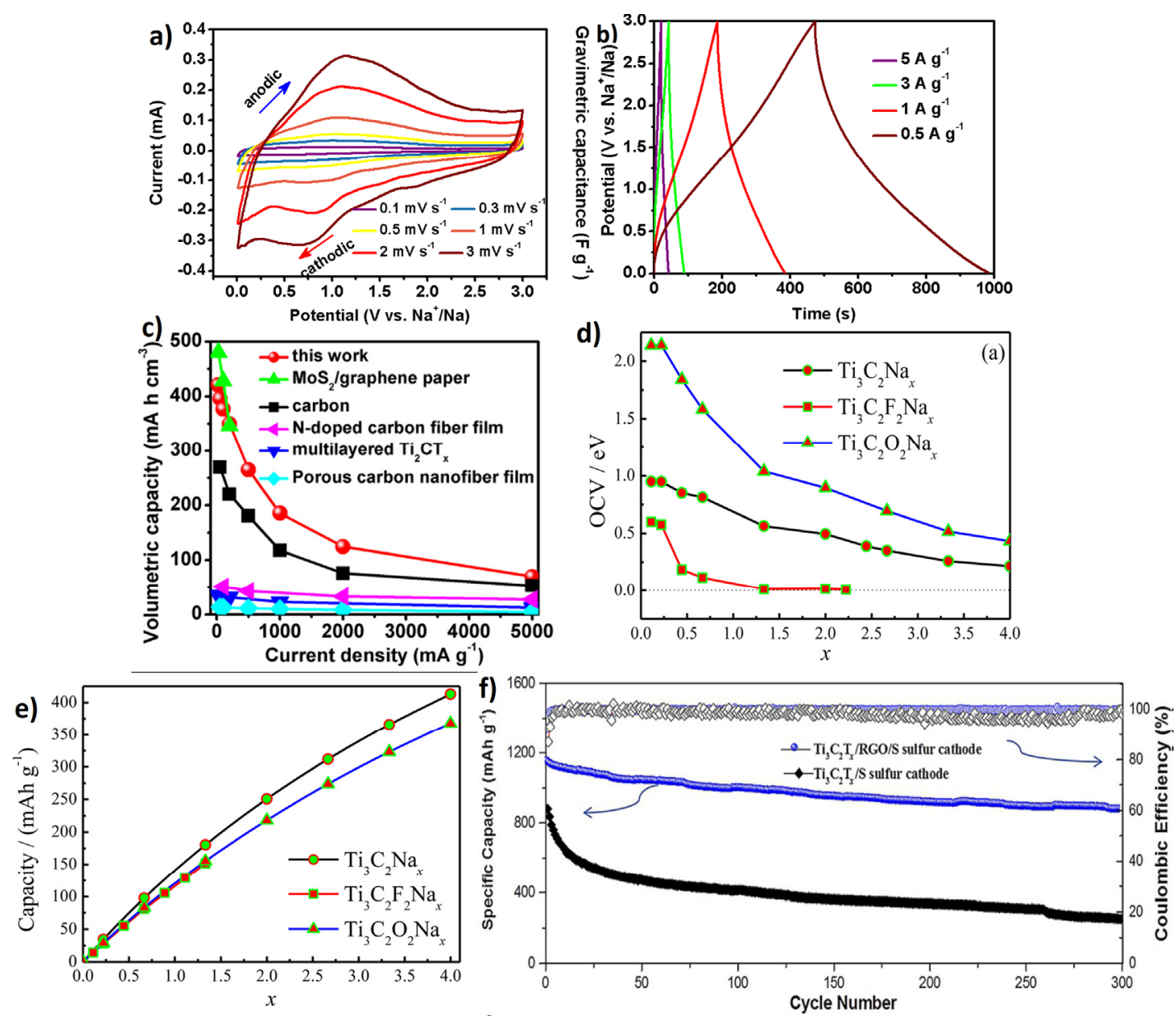

Figure 5. (a) Cyclic Voltammetry (CV) plots of the porous $\mathrm{Ti}_{3} \mathrm{C}_{2} \mathrm{~T}_{\mathrm{x}} / \mathrm{CNT}-\mathrm{SA}$ electrode at various scan rates between 0.1 to $3 \mathrm{mV} \mathrm{s}^{-1}$, (b) galvanostatic charge-discharge profiles at different current densities, (c) Volumetric capacities of $\mathrm{Ti}_{3} \mathrm{C}_{2} \mathrm{~T}_{x} / \mathrm{CNT}-\mathrm{SA},(\mathrm{d})$ Open-Circuit Voltage (OCV), (e) capacity as a function of $x$ in $\mathrm{Ti}_{3} \mathrm{C}_{2} \mathrm{~T}_{2} \mathrm{Na}_{x}$ with $\mathrm{T}=$ bare, $\mathrm{F}$, and $\mathrm{O}$ and (f) Discharge specific capacity and Coulombic efficiency of $\mathrm{Ti}_{3} \mathrm{C}_{2} \mathrm{~T}_{x} / \mathrm{RGO} / \mathrm{S}$ composite cathode. Reprinted with permission from $[82,84,85]$.

The lithium storage features of MXene-based materials rely on several factors like the functioning of 2D MXene and its byproducts for LIBs. This can be understood that the property can be modified by more prospects like surface decoration, functional group grafting, and variation of composition. Consequently, the rational nano-engineering of centered materials will vividly endorse their usage in LIB. Up to now, these are only restricted MXene materials with selected metal that have been prepared. So, adjusting the MXene components like metal species and a portion of metal/carbon will largely influence the performance of Li storage. Additional prospects like surface termination and interlayer distance are also significant to accommodate Li-ions. Through mixing MXenes with other effective materials with better capacity (such as silicon, metal oxides), the synergistic development can be accomplished. Enhancing the above-stated factors is the solution to get greater functioning of MXenes for LIB [83-85]. The MXene-based composite material is conceivable to be a promising high-performance anode material for LIBs [86-90]. Furthermore, various MXene based metal oxide composites were suggested for their use in energy storage applications.

\subsection{MXene for Energy Storage: Supercapacitors/Dielectrics}

MXenes also widely used in developing supercapacitors that are taken into account in replacements of energy storage devices due to elevated rates of charge/discharge compared to batteries and longer cycling stability. For example, multilayered $\mathrm{Ti}_{3} \mathrm{C}_{2} \mathrm{~T}_{\mathrm{x}}$ offered functioning of $340 \mathrm{~F} / \mathrm{cm}^{3}$ in $\mathrm{KOH}$ alkaline 
solutions [91], which is identical or finer than marketable activated and graphene carbon electrodes (correspondingly, 200-350 and $180 \mathrm{~F} / \mathrm{cm}^{3}$ ) [92]. When subjected to acidic solutions, such as $\mathrm{H}_{2} \mathrm{SO}_{4}$, the $\mathrm{Ti}_{3} \mathrm{C}_{2} \mathrm{~T}_{\mathrm{x}}$ film disclosed very good volumetric capacitance values $\left(900 \mathrm{~F} / \mathrm{cm}^{3}\right.$ at $2 \mathrm{mVs}^{-1}$ rate), even after 10,000 cycles, without degradation [91-93].

This dissimilar performance in acidic and alkaline electrolytes originates from the variance in the mechanism of the charge-discharge process. Whereas $\mathrm{Ti}_{3} \mathrm{C}_{2} \mathrm{~T}_{\mathrm{x}}$ has shown excellent pseudocapacitive properties in an acidic solution (e.g., $\mathrm{H}_{2} \mathrm{SO}_{4}$ ), only electrical double layer capacitance is observed in alkaline or neutral electrolytes that decreases their performance. Notably, pseudocapacitive performance is connected to closeness towards the electrode surfaces at, or the reversible surface redox reactions that give elevated energy density. Whereas, the double-layer capacitor depends on the reversible growth of electrolyte ions deprived of redox reactions. Subsequently, their decreased electrochemistry performances in basic and organic electrolytes are unfavorable steps towards realistic applications. Additionally, their charge storage processes above dissimilar electrolyte media are still to be completely implicit [94-96].

MXenes have a robust tendency of aggregation through hydrogen bonding and van der Waals attraction. This spoils their performance, mostly due to the lack of accessibility, the loss of surface area, and interchange of ions limitation. Therefore, other approaches have been adopted to resolve these issues, like usage of interlayer spacers, customized architectural designs (such as macroporous structure, hydrogel, or vertically aligned liquid-crystalline), the combination of these approaches and arrangement with conductive particles (e.g., $\mathrm{Nb}_{2} \mathrm{O}_{5}$ and $\mathrm{NiO}$ ) $[97,98]$. Other compounds, such as $\mathrm{Mo}_{2} \mathrm{CT}_{\mathrm{x}}$ [99] and $\mathrm{Mo}_{1.33} \mathrm{CT}_{\mathbf{x}}$ [100], also revealed promising functionality as supercapacitors. Regardless of the valuable effect of vacancies to $\mathrm{Mo}_{1.33} \mathrm{CT}_{x}$ capacitance (around $700 \mathrm{~F} / \mathrm{cm}^{3}, 65 \%$ higher than $\mathrm{Mo}_{2} \mathrm{CT}_{\mathrm{x}}$ ), their effect on electrochemical functioning yet needs to be further examined. Additionally, it was currently established that the flake size is quietly associated with the capacitance presentations. Ultimately, $\mathrm{Nb}_{3} \mathrm{C}_{2}$ projected quantum capacitance was greater than graphene, but neither this MXene, nor it's MAX phase precursors $\left(\mathrm{Nb}_{3} \mathrm{AlC}_{2}\right)$ have still been prepared, regardless of their projected stability [101,102].

Moreover, $\mathrm{Ti}_{3} \mathrm{C}_{2} \mathrm{~T}_{\mathrm{x}}$-polypyrrole nanocomposite $\left(1000 \mathrm{~F} / \mathrm{cm}^{3}\right)$ can almost reach the "new" $\left(\mathrm{Mo}_{2} / 3 \mathrm{Y}_{1} / 3\right)_{2} \mathrm{CT}_{\mathrm{x}}[103]$ and $\mathrm{Ti}_{3} \mathrm{C}_{2} \mathrm{~T}_{\mathrm{x}}$ [104] hydrogels performances $\left(\sim 1500 \mathrm{~F} / \mathrm{cm}^{3}\right)$ [39], that are among the best conveyed volumetric capacitance values for any capacitive compound (Table 3) [105]. Ultimately, regardless of many prepared MXenes, only molybdenum (Mo), titanium (Ti), and currently vanadium (V) derivatives were examined [106]. Therefore, other compounds must be assessed in turn to enlarge and improve the latest electrode materials of supercapacitors as the MXene based nanocomposites are highly suitable for the development of superior capacitors (Table 3).

Table 3. Summary of the capacitance of MXene and their composites.

\begin{tabular}{|c|c|c|c|c|}
\hline Materials & Synthesis Route & $\begin{array}{c}\text { Volumetric } \\
\text { Capacitance }\left(\mathrm{F} / \mathrm{cm}^{3}\right)\end{array}$ & $\begin{array}{l}\text { Scan Rate } \\
(\mathrm{mV} / \mathrm{s})\end{array}$ & Ref \\
\hline $90 \mathrm{wt} \% \mathrm{Ti}_{3} \mathrm{C}_{2} \mathrm{~T}_{\mathrm{x}} / 10 \mathrm{wt} \%$ PVA & HF etching & 528 & 2 & [31] \\
\hline $\mathrm{Ti}_{3} \mathrm{C}_{2} \mathrm{~T}_{\mathrm{x}}$ & Ball milling & 900 & 2 & {$[38]$} \\
\hline $88 \mathrm{wt} \%$ Mxene/GO fiber & $\begin{array}{l}\text { Liquid crystal-assisted } \\
\text { fiber spinning approach }\end{array}$ & 341 & 2 & {$[43]$} \\
\hline $\begin{array}{c}\text { Mxene/rGO-90 fiber } \\
\text { (containing } 90 \mathrm{w} / \mathrm{w} \% \text { of Mxene) }\end{array}$ & \multirow{2}{*}{ Wet spinning assembly } & 586.4 & 2 & {$[44]$} \\
\hline $\begin{array}{c}\text { Mxene/rGO-50 fiber } \\
\text { (containing } 50 \mathrm{w} / \mathrm{w} \% \text { of Mxene) }\end{array}$ & & 276 & 2 & {$[44]$} \\
\hline EGMX (1:9) & Solution process & 33 & 2 & {$[45]$} \\
\hline 2:1:1.1:2 $\mathrm{MO}_{2} \mathrm{TiC}_{2}$ & HF etching & 413 & 2 & [107] \\
\hline $2 \mathrm{D} \mathrm{MO}_{2} \mathrm{TiC}_{\mathrm{x}}$ & HCL-LiF & 196 & 2 & [108] \\
\hline $\mathrm{Ti}_{3} \mathrm{AlC}_{2} /$ Polypyrrole (2:1) & HCL-LiF & 416 & 5 & [109] \\
\hline
\end{tabular}


The dielectric permittivity and loss tangent of MXene/Polymer composites with variation in the MXene loading and different polymers have also been investigated (Figure 6a). It has been noticed that the dielectric permittivity of composites increases when MXene filler concentration increases. Figure $6 \mathrm{~b}$ shows the dielectric permittivity and loss of the polymer consisting of different types of fillers, including CNTs, rGO, and MXene. The dielectric constant of different types of insulating polymers [e.g., P(VDF-TrFE-CFE), P(VDF-TrFE-CTFE), P(VDF-TrFE), and PVP] increases significantly with the addition of $4 \mathrm{wt} \% \mathrm{MXene}$ (Figure $6 \mathrm{c}$ ). To understand the probable microwave absorption property, the relative complex permittivity and permeability of the prepared samples have also been measured in the frequency range of $2-18 \mathrm{GHz}$ and evaluated carefully in Figure $6 \mathrm{~d}$. The relative complex permeability $\left(\mu^{\prime}\right)$ values of the prepared MXene composites fluctuate over $2-18 \mathrm{GHz}$ and are less than 1.1. The $\mu^{\prime \prime}$ values of the prepared samples decreased from 0.78 to nearly 0 due to snoek's limitation (Figure 6e). Figure $6 \mathrm{f}$ describes the dielectric dissipation factors of the samples. From the figure, the pure iron sample has quite low dielectric loss factor. MXene composites have shown large tan $\delta$ values $[110,111]$.
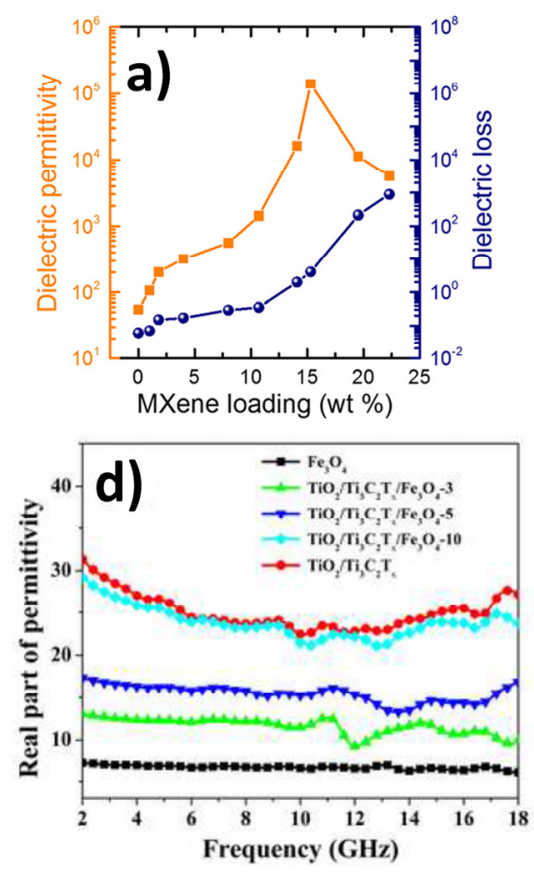
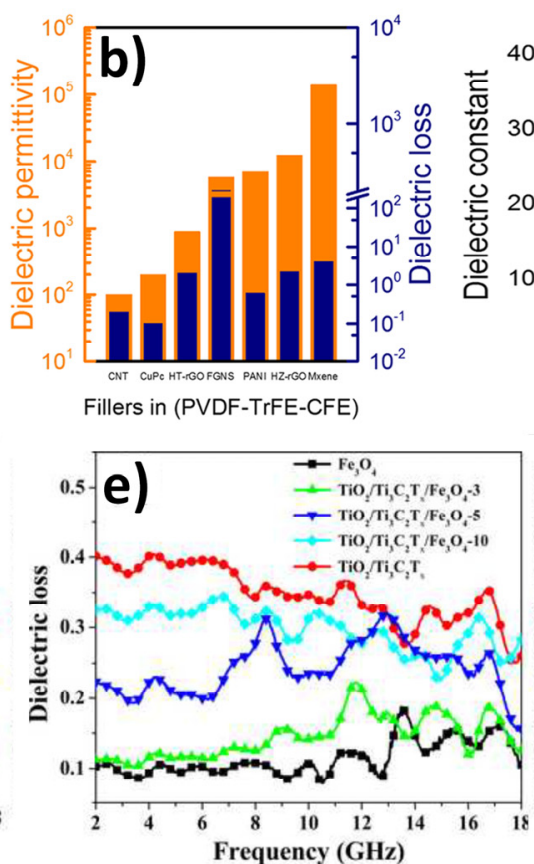
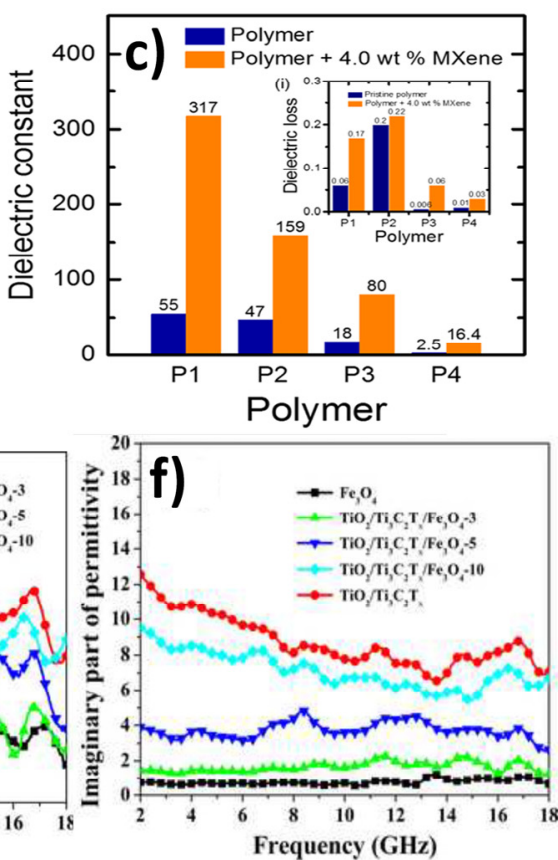

Figure 6. (a) Dielectric permittivity and loss of the MXene/Polymer composites on MXene content wt \% measured at RT and $1 \mathrm{kHz}$, (b) Bar charts comparing the dielectric permittivity and communicating loss described in the research report employing polymer as a matrix with diverse conductive fillers, (c) Dielectric constant of various polymers with and without MXene. Inset (i): Dielectric loss of diverse polymers inserted with MXene stacking; P1: P(VDF-TrFE-CFE); P2: P(VDF-TrFE-CTFE); P3: P(VDF-TrFE); P4: PVP, (d) Frequency dependence of (a) real part of permittivity and (f) imaginary parts of permeability for the $\mathrm{Fe}_{3} \mathrm{O}_{4}, \mathrm{TiO}_{2} / \mathrm{MXene}$, and $\mathrm{TiO}_{2} / \mathrm{MXene} / \mathrm{Fe}_{3} \mathrm{O}_{4}$ composites over $10-18 \mathrm{GHz}$ and (e) Dielectric dissipation factors of the $\mathrm{Fe}_{3} \mathrm{O}_{4}, \mathrm{TiO}_{2} / \mathrm{MXene}$, and $\mathrm{TiO}_{2} / \mathrm{MXene} / \mathrm{Fe}_{3} \mathrm{O}_{4}$ composites in the frequency range of 2-18 GHz. Copyright: Ref. 41 and 110.

From Table 4, the MXene-based polymer composites exhibit good dielectric property due to the charge accumulation caused by the formation of microscopic dipoles at the surface between the MXene and the polymer matrix under an external applied electric field. MXene with polymer composites is very useful in power capacitors, cryogenic electronics, and radiofrequency applications. 
Table 4. The dielectric constant and dielectric loss of MXene with different polymer composites.

\begin{tabular}{cccc}
\hline Materials & Dielectric Constant & Dielectric Loss & Ref. \\
\hline MXene/P (VDF-TrFE-CTFE) & 47 & 0.2 & {$[37]$} \\
\hline $4 \%$ MXene/P (VDF-TrFE-CTFE) & 159 & 0.22 & {$[37]$} \\
\hline MXene/P (VDF-TrFE) & 18 & 0.006 & {$[37]$} \\
\hline $4.3 \%$ MXene/P (VDF-TrFE) & 80 & 0.06 & {$[40]$} \\
\hline MXene/PVP & 2.5 & 0.01 & {$[40]$} \\
\hline $4 \%$ MXene/PVP & 16.4 & 0.03 & {$[40]$} \\
\hline MXene/P (VDF-TrFE-CFE) & 55 & 0.06 & {$[41]$} \\
\hline $4 \%$ MXene/P (VDF-TrFE-CFE) & 317 & 0.17 & {$[41]$} \\
\hline
\end{tabular}

\subsection{MXene for $\mathrm{CO}_{2}$ Conversion}

Due to suitable physical and chemical properties, MXene can potentially be used for $\mathrm{CO}_{2}$ storage and photo-, electrochemical reduction. Recently, $\mathrm{CO}_{2}$ storage on the surface of $\mathrm{M}_{2} \mathrm{C}$ MXene $(\mathrm{M}=$ transition metals such as $\mathrm{Ti}, \mathrm{Hf}, \mathrm{Zr}, \mathrm{V}, \mathrm{Ta}, \mathrm{Nb}, \mathrm{Mo}, \mathrm{W})(0001)$ is described by employing the state-of-the-art DFT PBE estimations comprising D3 Grimme correction dispersion. Outputs reveal elevated adsorption energies up to $3.69 \mathrm{eV}$ supplemented by a $\mathrm{CO}_{2}$ stimulation, converted into anionic $\mathrm{CO}_{2}$ d species with extended $\mathrm{d}(\mathrm{CO})$ bonds, bent structures, and an $\mathrm{MXene} / \mathrm{CO}_{2}$ charge transfer, unexpectedly above $2 \mathrm{e}$ for $\mathrm{Hf}_{2} \mathrm{C}[112,113]$. With these elevated adsorption energies, $\mathrm{M}_{2} \mathrm{C}$ MXenes are projected to be most efficient compared to their $3 \mathrm{D}$ bulk accompaniment for $\mathrm{CO}_{2}$ capturing, storage, and stimulation. 2D M $2 \mathrm{C}$ MXenes are introduced as potential materials for $\mathrm{CO}_{2}$ capture, whereas its stimulated adsorption is further enchanting for employing them as $\mathrm{CO}_{2}$ conversion catalysts [114-116].

The activity of transition metal carbides as $\mathrm{CO}_{2}$ conversion materials has been described by Zhou et al.'s that proved $\mathrm{M}_{2} \mathrm{CO}_{2}$ with an oxygen vacancy as an effective catalyst for $\mathrm{CO}_{2}$ reduction. Also, it should be noted that: (i) MXenes have broad metal-terminated surfaces, that may favor $\mathrm{CO}_{2}$ capturing; and (ii) MXenes shows metallic characters, that are useful for the different photo- and electrochemical reactions [117]. In particular, computing that chemical absorption of $\mathrm{CO}_{2}$ has favored over chemical absorption of $\mathrm{H}_{2} \mathrm{O}$ on their surfaces [118-120]. Additionally, the expectation that high electrical conductivity and the hydrophilic nature will accelerate an electrochemical reduction of $\mathrm{CO}_{2}$, in consideration of both giving electrons and $\mathrm{H}^{+}$attachment [121]. From this context, we assume that groups of IV-VI MXenes, such as carbides of transition-metal with formulas $M_{n+1} C_{n}(n=2)$, can work as efficient catalysts. $\mathrm{MoS}_{2} / \mathrm{Si}$ nanostructure exhibits good activity by the photoelectrochemical method (Figure $7 \mathrm{~A}, \mathrm{~B})$. The $\mathrm{CV}$ response of the $\mathrm{Bi} / \mathrm{C}$ electrode showed an electrochemical reduction of $\mathrm{CO}_{2}$ to formate at a scan rate of $50 \mathrm{mV} / \mathrm{s}$ (Figure $7 \mathrm{C}$ ). 

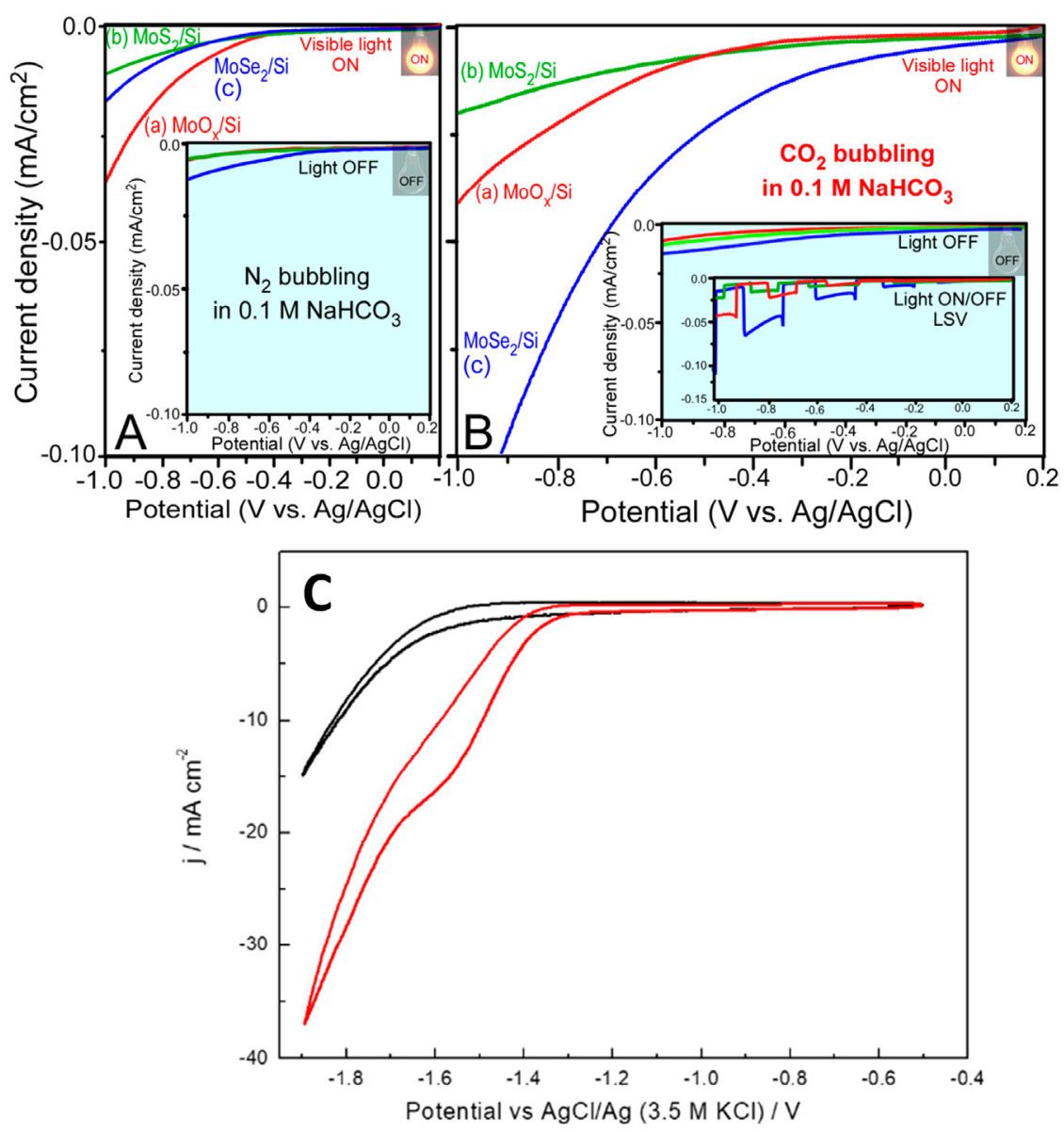

Figure 7. LSV curves in $\mathrm{N}_{2}(\mathrm{~A})$ and $\mathrm{CO}_{2}$ purged (B) $0.1 \mathrm{M} \mathrm{NaHCO}_{3}$ at a scan rate $(10 \mathrm{mV} / \mathrm{S})$ under dark; (C) CV response of Bi/C electrode in Ar (black line) and $\mathrm{CO}_{2}$ (red line) at a scan rate $(50 \mathrm{mV} / \mathrm{S}$ ). Reprinted with permission from $[122,123]$.

Photocatalytic $\mathrm{CO}_{2}$ conversion to beneficial products is an attractive methodology for attaining the two-fold profits of standardizing additional atmospheric $\mathrm{CO}_{2}$ stages and the fabrication of solar fuels/chemicals. Consequently, catalysts materials are constantly being established with improved functioning in agreement with their corresponding areas. Currently, nanostructured catalysts such as 1-D, 2-D, and 3-D/ hierarchical have been a theme of huge significance due to their precise benefits over composite catalytic materials, comprising huge surface areas, efficient charge separation, steering charge transport, and light trapping/scattering effects [124-127]. A hierarchical heterostructured, selectively $\mathrm{Ti}_{3} \mathrm{C}_{2}$ quantum dots decorated $\mathrm{Cu}_{2} \mathrm{O}$ nanowires on $\mathrm{Cu}$ mesh, has been fabricated via easy electrostatic self-assembly. Formation of methanol ensuing from the photocatalytic reduction of $\mathrm{CO}_{2}$ by $\mathrm{Ti}_{3} \mathrm{C}_{2}$ quantum dots $/ \mathrm{Cu}_{2} \mathrm{O}$ nanowires/Cu is 8.25 times or 2.15 times of that from $\mathrm{Cu}_{2} \mathrm{O}$ nanowires $/ \mathrm{Cu}$ or $\mathrm{Ti}_{3} \mathrm{C}_{2}$ sheets $/ \mathrm{Cu}_{2} \mathrm{O}$ nanowires/Cu, correspondingly [48]. From Table 5 , the $\mathrm{TiO}_{2}$ based nanocomposites are highly useful in the photoelectrochemical conversion of $\mathrm{CO}_{2}$ to fuels. 
Table 5. Summary of the photochemical catalytic reduction performance of the various reported composite materials.

\begin{tabular}{|c|c|c|c|}
\hline Materials & Light Source & Catalytic Performance & Ref. \\
\hline Sulfur doped g- $\mathrm{C}_{3} \mathrm{~N}_{4} / \mathrm{Pt}$ & $300 \mathrm{~W}$ Xenon lamp & $\mathrm{CH}_{3} \mathrm{OH}: 0.04 \mu \mathrm{molh}^{-1}$ & [49] \\
\hline $\mathrm{g}-\mathrm{C}_{3} \mathrm{~N}_{4} / \mathrm{N}-\mathrm{TiO}_{2}$ nanosheets & $300 \mathrm{~W}$ Xenon lamp & $\begin{array}{l}\mathrm{CO}: 14.73 \mu \mathrm{molg}^{-1} \\
\mathrm{CH}_{4}: 03.94 \mu \mathrm{molg}^{-1}\end{array}$ & [117] \\
\hline $\mathrm{TiO}_{2} / \mathrm{Ti}_{3} \mathrm{C}_{2}$ & $300 \mathrm{~W}$ Xenon lamp & $\mathrm{CH}_{4}=0.22 \mu \mathrm{molh}^{-1}$ & [128] \\
\hline Graphene QDs- $\mathrm{TiO}_{2}$ nanotube arrays (TNT) & $100 \mathrm{~W}$ Xenon lamp & $\mathrm{CH}_{4}: 1.98 \mathrm{ppmcm}^{-2} \mathrm{~h}^{-1}$ & [129] \\
\hline TNT-rGO & $100 \mathrm{~W}$ Xenon lamp & $\mathrm{CH}_{4}: 5.67 \mathrm{ppmcm}^{-2} \mathrm{~h}^{-1}$ & {$[130]$} \\
\hline Ordered mesoporous co-doped $\mathrm{TiO}_{2}$ & $300 \mathrm{~W}$ Xenon lamp & CO: $0.19 \mu \mathrm{molh}^{-1}$ & {$[131]$} \\
\hline $\mathrm{TiO}_{2} / \mathrm{Mg}$ & $300 \mathrm{~W}$ Xenon lamp & $\mathrm{CH}_{4}: 0.15 \mu \mathrm{molg}^{-1}$ & [132] \\
\hline $\mathrm{Cu}$ modified g- $\mathrm{C}_{3} \mathrm{~N}_{4}$ sheets with $\mathrm{TiO}_{2}$ nanoparticles & $500 \mathrm{~W}$ Xe lamp & $\begin{array}{l}\mathrm{CH}_{3} \mathrm{OH}: 614 \mu \mathrm{molg}^{-1} \\
\mathrm{HCOOH}: 6709 \mu \mathrm{molg}^{-1}\end{array}$ & [133] \\
\hline 2-D-g- $\mathrm{C}_{3} \mathrm{~N}_{4}$ with o-D- $\mathrm{TiO}_{2-\mathrm{x}}$ nanoparticles & $300 \mathrm{~W}$ Xenon lamp & $\mathrm{CO}: 388.9 \mu \mathrm{molg}^{-1}$ & [134] \\
\hline $\begin{array}{c}\text { Graphene- }-\mathrm{TiO}_{2} \text { nanostructures } \\
\text { (nanoparticles, nanotubes, nanosheets) }\end{array}$ & $300 \mathrm{~W}$ Xenon lamp & $\begin{array}{l}\mathrm{CO}: 75.8 \mu \mathrm{molg}^{-1} \mathrm{~h}^{-1} \\
\mathrm{CH}_{4}: 12.3 \mu \mathrm{molg}^{-1} \mathrm{~h}^{-1}\end{array}$ & [135] \\
\hline
\end{tabular}

In terms of $\mathrm{CO}_{2}$ electrochemical reduction reaction $\left(\mathrm{CO}_{2} \mathrm{RR}\right)$, different types of MXenes (e.g., $\mathrm{Ti}_{2} \mathrm{CO}_{2}$, $\mathrm{V}_{2} \mathrm{CO}_{2}$, and $\mathrm{Ti}_{3} \mathrm{C}_{2} \mathrm{O}_{2}, \mathrm{M}_{3} \mathrm{C}_{2}$, O-terminated MXenes, and -OH-terminated MXenes) have been examined by means of DFT computations [136].

An initial computational study has suggested that among eight different MXenes (pristine and without surface termination) with formula $\mathrm{M}_{3} \mathrm{C}_{2}$ where M belongs to group IV, $\mathrm{V}$, and VI transition-metal, can potentially convert $\mathrm{CO}_{2}$ into hydrocarbon electrochemically. It has been mentioned that $\mathrm{Cr}_{3} \mathrm{C}_{2}$ and $\mathrm{Mo}_{3} \mathrm{C}_{2}$ with a minimum energy input of 1.05 and $1.31 \mathrm{eV}$, respectively, can selectively convert $\mathrm{CO}_{2}$ into methane. The required input energy can be further reduced to 0.35 and $0.54 \mathrm{eV}$ by using $-\mathrm{O}$ or $-\mathrm{OH}$ terminated $\mathrm{Cr}_{3} \mathrm{C}_{2}$ and $\mathrm{Mo}_{3} \mathrm{C}_{2}$, respectively. Therefore, Chen et al. perform additional computational study for $-\mathrm{OH}$ terminated carbide and nitride MXenes [137]. $\mathrm{Sc}_{2} \mathrm{C}(\mathrm{OH})_{2}$ and $\mathrm{Y}_{2} \mathrm{C}(\mathrm{OH})_{2}$ were suggested to be the most promising catalysts for the selective production of methane via $\mathrm{CO}_{2} \mathrm{RR}$. Both catalysts can reduce $\mathrm{CO}_{2}$ at significantly less negative potential than the $\mathrm{Cu}$ metal. Here it should be noted that most of the standard nanocatalysts except $\mathrm{Cu}$ are not able to produce higher carbon products during $\mathrm{CO}_{2} \mathrm{RR}$ [138]. For instance, $\mathrm{Au}$ and Ag-based nanocatalysts produce only carbon monoxide $(\mathrm{CO})$ as a $\mathrm{CO}_{2} \mathrm{RR}$ product. However, $\mathrm{Cu}$ based nanocatalysts can produce hydrocarbon but suffer from poor selectivity, as discussed in our previous review [139]. Thus, we predict that MXene-based catalysts offer a breakthrough in $\mathrm{CO}_{2} \mathrm{RR}$ but still need to be examined experimentally.

\subsection{MXene for Proton Reduction}

Hydrogen is an excellent energy carrier could potentially replace carbon-based fuel if it is produced via clean and sustainable technology. In this regard, hydrogen production via hydrogen evolution reaction (HER) using renewable energy sources offer a feasible approach. Apart from noble metal catalysts (e.g., Pt, Pd), 2D nanomaterials, including transition metal dichalcogenides such as $\mathrm{MoS}_{2}, \mathrm{WS}_{2}$, and their hybrid structures are reportedly excellent catalysts for HER [140]. With the discovery of MXene, recent efforts are directed towards exploring the HER catalytic activity of these nanomaterials [141].

Theoretical and experimental studies have been performed to investigate the HER activity of MXene. Initially, Zhi et al. performed density-functional theory (DFT) estimations to establish $\Delta \mathrm{G}_{\mathrm{H}}$ (hydrogen adsorption Gibbs free energy) on MXenes, followed by experiments to verify their DFT results [142]. Based on DFT calculation, $\mathrm{Mo}_{2} \mathrm{CT}_{x}$ was predicted to be more functional catalyst due to smaller $\Delta G_{\mathrm{H}}$ and theoretical overpotential $(0.048 \mathrm{eV}, 48 \mathrm{mV}$ respectively) in comparison to the $\mathrm{Ti}_{2} \mathrm{CT}_{x}(0.358 \mathrm{eV}, 358 \mathrm{mV}$ respectively). Recently, Yu-Wen Cheng et al. also performed DFT study, and 
their results indicate the higher HER activity of $\mathrm{O}^{*}$-terminated $\mathrm{M}_{2}{ }^{\prime} \mathrm{M}^{\prime \prime} \mathrm{C}_{2}$ due to appropriate binding strength between hydrogen absorption and termination of $\mathrm{O}^{*}$, and availability of more electrons [143]. When both materials were tested in $0.5 \mathrm{M} \mathrm{H}_{2} \mathrm{SO}_{4}(\mathrm{aq}), 609 \mathrm{mV}$ and $189 \mathrm{mV}$ overpotential were recorded for $\mathrm{Ti}_{2} \mathrm{CT}_{\mathrm{x}}$ and $\mathrm{Mo}_{2} \mathrm{CT}_{x}$ at a current density of $10 \mathrm{~mA} \mathrm{~cm}^{-2}$ geo respectively. The superior activity of $\mathrm{Mo}_{2} \mathrm{CT}_{x}$ was accredited to the existence of active sites located on the basal plane. Further, Guoxing $\mathrm{Qu}$ et al. synthesized phosphorus-doped $\mathrm{Mo}_{2} \mathrm{C} T_{x}$ MXenes $\left(\mathrm{P}-\mathrm{Mo}_{2} \mathrm{C} T_{x}\right)$ and compared the results with un-doped $\mathrm{Mo}_{2} \mathrm{CT}_{x}$ MXenes and commercial Pt/C (Figure 8a,b) [144].
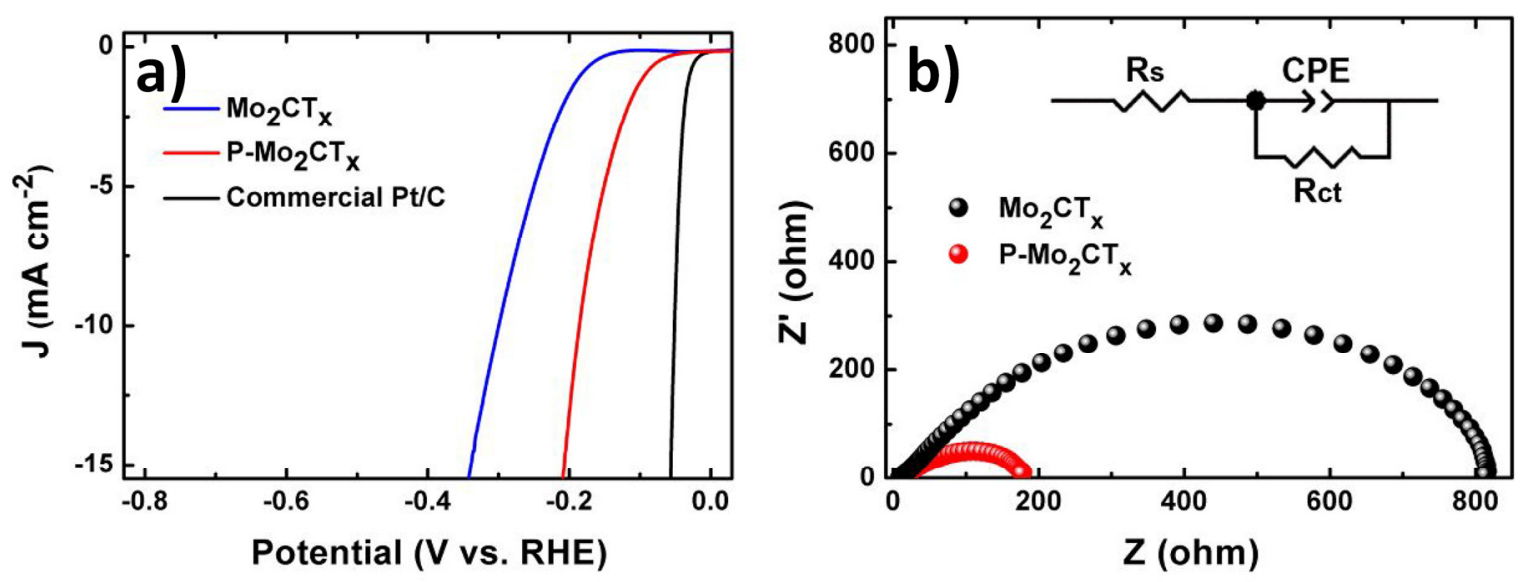

Figure 8. (a) Mo2CTx, P-Mo2CTx-HER polarization curves, and commercial $\mathrm{Pt} / \mathrm{C}(20 \mathrm{wt} \% \mathrm{Pt}$. (b) EIS of Mo2CTx and P-Mo2CTx. Reprinted with permission from [144].

It has been argued that dopant enhances the conductivity of the materials as evidence by $\sim 5$ times lower charge transfer resistance (Rct) than that of without dopant and reduces the $\Delta G_{\mathrm{H}^{*}}$ simultaneously. More interestingly, $\mathrm{P}-\mathrm{Mo}_{2} \mathrm{CT}_{x}$ was stable for $24 \mathrm{~h}$ in acidic media. Wenjin Yuan et al. examined the HER activity of lamellar $\mathrm{Mo}_{2} \mathrm{C}\left(\mathrm{L}-\mathrm{Mo}_{2} \mathrm{C}\right)$ and interestingly $10 \mathrm{~mA} \mathrm{~cm}^{-2}$ geo current density was achieved at only $95.8 \mathrm{mV}$ and $170 \mathrm{mV}$ overpotential in $1 \mathrm{M} \mathrm{KOH}$ and $0.5 \mathrm{M} \mathrm{H}_{2} \mathrm{SO}_{4}$ solution, correspondingly [145]. The superior HER activity of $\mathrm{L}-\mathrm{Mo}_{2} \mathrm{C}$ was mainly attributed to the lower value of $\Delta G_{\mathrm{H}}(-0.034 \mathrm{eV})$ of the $\mathrm{C}$-terminal (1 00 ) plane in $\mathrm{Mo}_{2} \mathrm{C}$. Due to the participation of $\mathrm{C}$ atoms in $\mathrm{HER}, \mathrm{L}-\mathrm{Mo}_{2} \mathrm{C}$ exhibits superior stability, avoiding poisoning phenomena due to oxidation of atoms. Extracted Tafel slopes of 77 and $99 \mathrm{mV} \mathrm{dec}{ }^{-1}$ in alkaline and acidic solution correspondingly indicate that HER on L-Mo $2 \mathrm{C}$ is governed by Volmer-Heyrovsky mechanism. Based on a theoretical study, V-based catalysts should also exhibit excellent HER catalytic activity. Thus, Minh $\mathrm{H}$. Tran et al. synthesized $\mathrm{V}_{4} \mathrm{C}_{3} T_{x}$ and examined HER activity [146]. However, the results claim poor performance of $\mathrm{V}_{4} \mathrm{C}_{3} T_{x}$ as $10 \mathrm{~mA} \mathrm{~cm}{ }^{-2}$ geo current density was observed at $\sim-800 \mathrm{mV}$, and a high Tafel slop $(\sim 236 \mathrm{mV} / \mathrm{dec})$ was calculated. Surprisingly, the performance of the catalysts improves after 100 cycles, and $10 \mathrm{~mA} \mathrm{~cm}^{-2}$ geo current density has been obtained at $200 \mathrm{mV}$ lower overpotential. Compare to nanoparticles or nanoflakes MXene, MXene nano-fibers exhibit superior HER activity due to the simple enhancement in an extreme specific surface area (SSA), and thus, the availability of additional active sites. The catalytic activity can be further boosted by the creation of interface or hybrid structure. Thus, Jie Xiong et al. created $\mathrm{Mo} / \beta-\mathrm{Mo}_{2} \mathrm{C}$ hetero-nanosheets and identified that $\mathrm{Mo} / \beta-\mathrm{Mo}_{2} \mathrm{C}$ nanocatalysts require only $89 \mathrm{mV}$ to drive HER with a current density of $10 \mathrm{~mA} \mathrm{~cm}^{-2}$ geo in $0.5 \mathrm{M} \mathrm{H}_{2} \mathrm{SO}_{4}$ [147]. More importantly, $\mathrm{Mo} / \beta-\mathrm{Mo}_{2} \mathrm{C}^{\prime}$ s HER activity remains approximately unaffected after $20 \mathrm{~h}$ of long chronoamperometric electrolysis or $4000 \mathrm{I}-\mathrm{V}$ sweeps. Again the origin for improved catalytic activity was assumed due to lower $\Delta G_{\mathrm{H}}(-0.04 \mathrm{eV})$ for $\mathrm{Mo} / \beta-\mathrm{Mo}_{2} \mathrm{C}$ compared to those of individual $\mathrm{Mo}(-0.39)$ and $\beta-\mathrm{Mo}_{2} \mathrm{C}(-0.19 \mathrm{eV})$. Considering that the basal plan is responsible for higher HER activity, Albertus D. Handoko performed controlled experiments by varying the degree of basal plan functionality using $\operatorname{Ti}_{3} C_{2} T_{x}$ as an example [148]. DFT calculations, along with experimental results, confirm that replacing $\mathrm{O}$ with $\mathrm{F}$ (fluorine) on basal plan results in higher $\Delta G_{\mathrm{H}}$ and HER overpotential. Recently $\mathrm{Ti}_{3} \mathrm{C}_{2} \mathrm{~T}_{x}$ and $\mathrm{MoS}_{2}$ hybrid catalysts 
were also designed in search of efficient HER catalysts [149]. In brief, "nanoroll" like $\mathrm{MoS}_{2} / \mathrm{Ti}_{3} \mathrm{C}_{2} \mathrm{~T}_{\mathrm{x}}$ hybrid structure was synthesized by quick freezing of the $\mathrm{Ti}_{3} \mathrm{C}_{2} \mathrm{~T}_{x}$ and $\mathrm{MoS}_{2}$ precursor (ammonium tetrathiomolybdate) followed by annealing in $\mathrm{H}_{2} / \mathrm{Ar}(20 \% / 80 \%)$ atmosphere with a heating rate of $5{ }^{\circ} \mathrm{C} / \mathrm{min}$. The HER results show relatively improved performance as HER initiate only at $30 \mathrm{mV}$, and an approximately 25-fold rise in the exchange current density in comparison to the $\mathrm{MoS}_{2}$ nanoflakes. Double transition metal MXene nanosheets $\left(\mathrm{Mo}_{2} \mathrm{TiC}_{2} \mathrm{~T}_{x}\right)$ consisting of Mo vacancies in outer layers have also been used to immobilize Pt atom and examined for HER [150]. In this configuration, due to solid covalent interaction among positively charged $\mathrm{Pt}$ single atoms and the MXene, it has unusual high HER activity. The HER takes place at very low potential, and 10 , and $100 \mathrm{~mA} \mathrm{~cm}^{-2}$ current densities were recorded only at 30 and $77 \mathrm{mV}$ over potential, respectively (Table 6).

MXene based nanomaterials (Table 6) showed the high overpotential at $10 \mathrm{~mA} \mathrm{~cm}^{-2}$ in $0.5 \mathrm{M}$ $\mathrm{H}_{2} \mathrm{SO}_{4}$ medium (HER activity) due to the increased reaction content area is profitable to the interaction between Mxenes and hydrogen atoms.

Table 6. HER activity of different 2D nanomaterials with different media.

\begin{tabular}{cccc}
\hline Materials & Over Potential at $\mathbf{1 0 ~} \mathbf{~ m A ~ c m}{ }^{-2}{ }_{\text {geo }}$ & Media (Aqueous Solution) & Reference \\
\hline $\mathrm{Mo}_{2} \mathrm{CT}_{x}$ & $300 \mathrm{mV}$ & $0.5 \mathrm{M} \mathrm{H}_{2} \mathrm{SO}_{4}$ & {$[142]$} \\
\hline${\mathrm{P}-\mathrm{Mo}_{2} \mathrm{CT}}_{x}$ & $186 \mathrm{mV}$ & $0.5 \mathrm{M} \mathrm{H}_{2} \mathrm{SO}_{4}$ & {$[142]$} \\
\hline $\mathrm{Mo}_{2} \mathrm{CT}_{\mathrm{X}} \mathrm{MXene}$ & $283 \mathrm{mV}$ & $0.5 \mathrm{M} \mathrm{H}_{2} \mathrm{SO}_{4}$ & {$[142]$} \\
\hline $\mathrm{MoS}_{2}$ & $280 \mathrm{mV}$ & $0.5 \mathrm{M} \mathrm{H}_{2} \mathrm{SO}_{4}$ & {$[142]$} \\
\hline $\mathrm{Ti}_{2} \mathrm{CT}_{x}$ & $609 \mathrm{mV}$ & $0.5 \mathrm{M} \mathrm{H}_{2} \mathrm{SO}_{4}$ & {$[143]$} \\
\hline $\mathrm{Mo}_{2} \mathrm{CT}_{x}$ & $189 \mathrm{mV}$ & $0.5 \mathrm{M} \mathrm{H}_{2} \mathrm{SO}_{4}$ & {$[143,148]$} \\
\hline $\mathrm{L}-\mathrm{Mo}_{2} \mathrm{C}\left(\right.$ lamellar structure $\left.\beta-\mathrm{Mo}_{2} \mathrm{C}\right)$ & $170 \mathrm{mV}$ & $0.5 \mathrm{M} \mathrm{H}_{2} \mathrm{SO}_{4}$ & {$[145]$} \\
\hline $\mathrm{L}-\mathrm{Mo}_{2} \mathrm{C}\left(\right.$ lamellar structure $\left.\beta-\mathrm{Mo}_{2} \mathrm{C}\right)$ & $95.8 \mathrm{mV}$ & $1 \mathrm{M} \mathrm{KOH}$ & {$[145]$} \\
\hline $\mathrm{Ti}_{3} \mathrm{C}_{2}$ nanofibers & $169 \mathrm{mV}$ & $0.5 \mathrm{M} \mathrm{H}_{2} \mathrm{SO}_{4}$ & {$[149]$} \\
\hline $\mathrm{Ti}_{3} \mathrm{C}_{2}$ flakes & $385 \mathrm{mV}$ & $0.5 \mathrm{M} \mathrm{H}_{2} \mathrm{SO}_{4}$ & {$[149]$} \\
\hline $\mathrm{MoS}_{2} / \mathrm{Ti}_{3} \mathrm{C}_{2} \mathrm{~T}_{\mathrm{x}}$ & $152 \mathrm{mV}$ & $0.5 \mathrm{M} \mathrm{H}_{2} \mathrm{SO}_{4}$ & {$[149]$} \\
\hline
\end{tabular}

\subsection{MXene for Oxygen Reduction Reaction}

The developments of cutting-edge skills, like fuel cells and metal-air batteries, afford great potential and supportable replacement solutions to challenge environmental issues and increasing severe energy [151-153]. Extremely active and long-lasting electrocatalysts for cathodic oxygen reduction reaction (ORR) are crucial for the extensive range of applications in fuel cells [154]. The state-of-the-art catalysts are importantly dependent on noble metals such as platinum $(\mathrm{Pt})$, but the costly, inadequate resources and worse durability have considerably hindered the marketing of the Pt-grounded fuel cells. Based on this, the investigation of economically cheap metal catalysts has been a leading theme of the electrocatalysts [155]. During the past, many efforts have been made to expand even metal-free alternatives or non-Pt family metals as ORR catalysts. Particularly, the quick growth has been accomplished on metal-free ORR electrocatalysts, such as heteroatom-doped graphene, mesoporous carbons, and CNTs [156]. Currently, investigations on electrocatalysts of MXenes and MXene nanocomposites have got much attentiveness $[157,158]$. MXenes, holding hydrophilic surface with protuberant stability and conductivity, can be predictable as assuring electrocatalysts. Specifically, the recent literature has concentrated on the MXene composites for electrocatalysts, such as the overlay of $\mathrm{g}-\mathrm{C}_{3} \mathrm{~N}_{4}$ and $\mathrm{Ti}_{3} \mathrm{C}_{2}$ nanosheets (Figure 9) composites (TCCN) as a catalyst for ORR process [159]. 

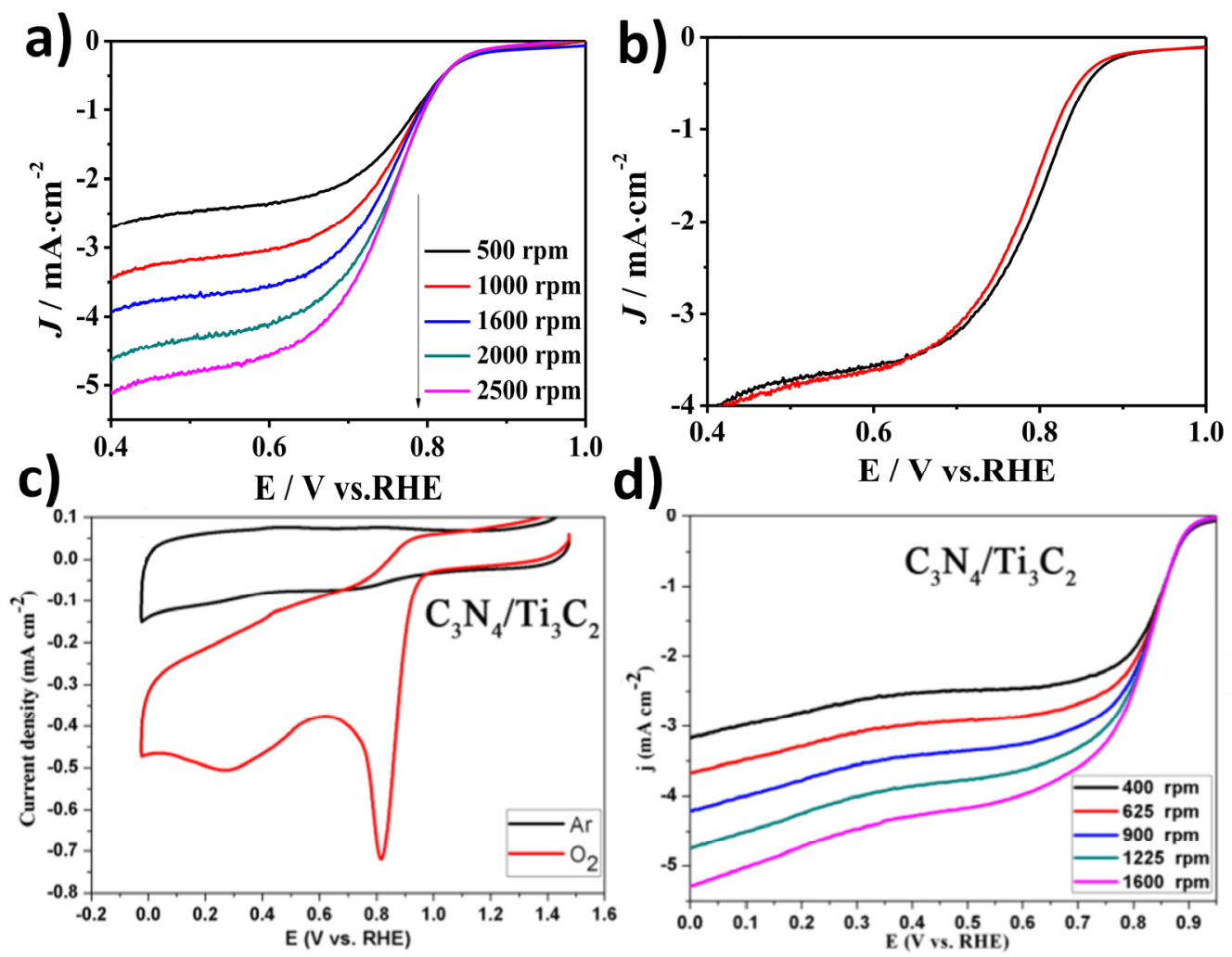

Figure 9. (a) Linear Sweep Voltammetry (LSV) curves of $\mathrm{MoS}_{2} \mathrm{QDs} @ \mathrm{Ti}_{3} \mathrm{C}_{2} \mathrm{~T}_{x} \mathrm{QDs} @ \mathrm{MWCNTs}-2$ in $\mathrm{O}_{2}$-saturated $1.0 \mathrm{M} \mathrm{KOH}$ solution at a scan rate of $5 \mathrm{mV} \mathrm{s}^{-1}$ with diverse rotation speeds, (b) ORR polarization curves of $\mathrm{MoS}_{2} \mathrm{QDs} @ \mathrm{Ti}_{3} \mathrm{C}_{2} \mathrm{~T}_{x} \mathrm{QDs} @ \mathrm{MWCNTs}-2$ before and after 1,000 potential cycles, (c) $\mathrm{CV}$ curves of $\mathrm{CT}$-modified electrodes in $\mathrm{O}_{2}$-saturated and $\mathrm{Ar}$-saturated $\mathrm{KOH}$ solution and (d) CT2-modified electrodes at various rotation rates in $\mathrm{O}_{2}$-saturated $\mathrm{KOH}$ solution. Copyright: Ref. [51,52].

The $\mathrm{Ti}_{3} \mathrm{C}_{2}$ MXene-based catalyst has shown excellent ORR activity and stability in the basic medium $[160,161]$. Through a sandwich-like form comprising of titanium atoms at the terminals or the surface layer and carbon atoms at the innermost layer, the catalyst is a flawless model system for the interpretation of the ORR active sites of this type of 2D layer-by-layer catalysts. This provides a new route to apply $\mathrm{Ti}_{3} \mathrm{C}_{2}$ MXene-based catalysts for efficient ORR activity and stability in the basic medium for fabricating greater-functioning and economically cheap electrocatalysts [47].

$\mathrm{X} Y \mathrm{u}$ et al. have prepared a facile fabrication of $\mathrm{g}-\mathrm{C}_{3} \mathrm{~N}_{4}$ nanosheets with $\mathrm{Ti}_{3} \mathrm{C}_{2}$ nanoparticles. The $\mathrm{gC}_{3} \mathrm{~N}_{4} / \mathrm{Ti}_{3} \mathrm{C}_{2}$ hybrid-structures show a significant improvement for ORR than that of pure $\mathrm{g}-\mathrm{C}_{3} \mathrm{~N}_{4}$ nanosheets (Figure 9c,d). Also, the electrocatalytic activity is intensely depending on the stacking amount of $\mathrm{Ti}_{3} \mathrm{C}_{2}$ nanoparticles. The optimal stacking quantity of $\mathrm{Ti}_{3} \mathrm{C}_{2}$ to $\mathrm{g}-\mathrm{C}_{3} \mathrm{~N}_{4}$ is about $2 \mathrm{wt} \%$. The enhanced catalytic performance is ascribed to the improved oxygen adsorption and well-organized charge separation because of the electronic coupling among $\mathrm{g}-\mathrm{C}_{3} \mathrm{~N}_{4}$ and $\mathrm{Ti}_{3} \mathrm{C}_{2}$. Predominantly, contrasted with the marketable $\mathrm{Pt} / \mathrm{C}$, the $\mathrm{g}-\mathrm{C}_{3} \mathrm{~N}_{4} / \mathrm{Ti}_{3} \mathrm{C}_{2}$ hybrid-structures reveal good methanol tolerance then again with no intake of valuable metals [52]. The theoretical study has suggested that $\mathrm{V}_{2} \mathrm{C}$ and $\mathrm{Mo}_{2} \mathrm{C}$ MXenes with $\mathrm{N}$-doped graphene can potentially be used for ORR due to very low ORR overpotential, i.e., $0.36 \mathrm{~V}$, and low kinetics barriers due to electronic coupling between the n-doped graphene and the MXene [158].

The $\mathrm{MoS}_{2} \mathrm{QDs} @ \mathrm{Ti}_{3} \mathrm{C}_{2} \mathrm{~T}_{\mathrm{x}} \mathrm{QDs} @ \mathrm{MMWCNT}$ catalyst (Figure 9a,b) also shows a superior ORR mechanism to other non-Pt catalysts, providing a low Tafel slope of $90 \mathrm{mV} \mathrm{dec}{ }^{-1}$ and greater half potential like $\mathrm{E}_{1 / 2}, 0.75 \mathrm{~V}$, that was near to their marketable Pt/C $(20 \%)$ catalyst $\left(\mathrm{E}_{1 / 2}\right.$ of $0.80 \mathrm{~V}$, Tafel slope of $89 \mathrm{mV} \mathrm{dec}^{-1}$ ) [162-166]. Besides, the $\mathrm{MoS}_{2} \mathrm{QDs} @ \mathrm{Ti}_{3} \mathrm{C}_{2} \mathrm{~T}_{\mathrm{x}} \mathrm{QDs} @ M M W C N T s$ (Figure 10) also hold better electro-oxidation activity for methanol in basic solution, providing current density at $2.2 \mathrm{~V}$ 
of $160 \mathrm{~A} \cdot \mathrm{g}^{-1}$ with extreme methanol oxidation. The outputs signified that the grouping of $\mathrm{MoS}_{2}$ and $\mathrm{Ti}_{3} \mathrm{C}_{2} \mathrm{~T}_{\mathrm{x}}$ QDs with MWCNTs could provide a potential for producing the bifunctional electrocatalysts for MOR and ORR [167-174]. From Table 7, Fe doped MXene materials show high oxygen reduction reaction activity (half-wave potential) due to increased oxygen adsorption and charge separation.

Table 7. Summary of the ORR activity for the synthesized MXene composites with recently reported highly active electrocatalysts.

\begin{tabular}{|c|c|c|c|c|}
\hline Catalyst & Load Mass $\left(\mathrm{mg} / \mathrm{cm}^{2}\right)$ & Electrolyte & Half-Wave Potential & Ref \\
\hline $\mathrm{FeN}_{\mathrm{x}}$ embedded in 2D porous nitrogen doped carbon & 0.14 & $0.1 \mathrm{M} \mathrm{KOH}$ & $0.86 \mathrm{~V}$ & [46] \\
\hline B, Fe doped porous carbon & 0.6 & $0.1 \mathrm{M} \mathrm{KOH}$ & $0.838 \mathrm{~V}$ & [50] \\
\hline Fe isolated single atoms on $\mathrm{S}, \mathrm{N}$ co-doped carbon & 0.51 & $0.1 \mathrm{M} \mathrm{KOH}$ & $0.896 \mathrm{~V}$ & [51] \\
\hline MXene & 0.1 & $0.1 \mathrm{M} \mathrm{KOH}$ & $0.75 \mathrm{~V}$ & [65] \\
\hline Fe-N-C/MXene & 0.1 & $0.1 \mathrm{M} \mathrm{KOH}$ & $0.84 \mathrm{~V}$ & [65] \\
\hline Fe-N co-doped carbon nanotubes & 0.1 & $0.1 \mathrm{M} \mathrm{KOH}$ & $0.83 \mathrm{~V}$ & [163] \\
\hline Fe-N-co-doped carbon frame & 0.5 & $0.1 \mathrm{M} \mathrm{KOH}$ & $0.7 \mathrm{~V}$ & [165] \\
\hline Fe-N-co-doped carbon frame & 0.5 & $0.1 \mathrm{M} \mathrm{HClO}_{4}$ & $0.77 \mathrm{~V}$ & [165] \\
\hline
\end{tabular}

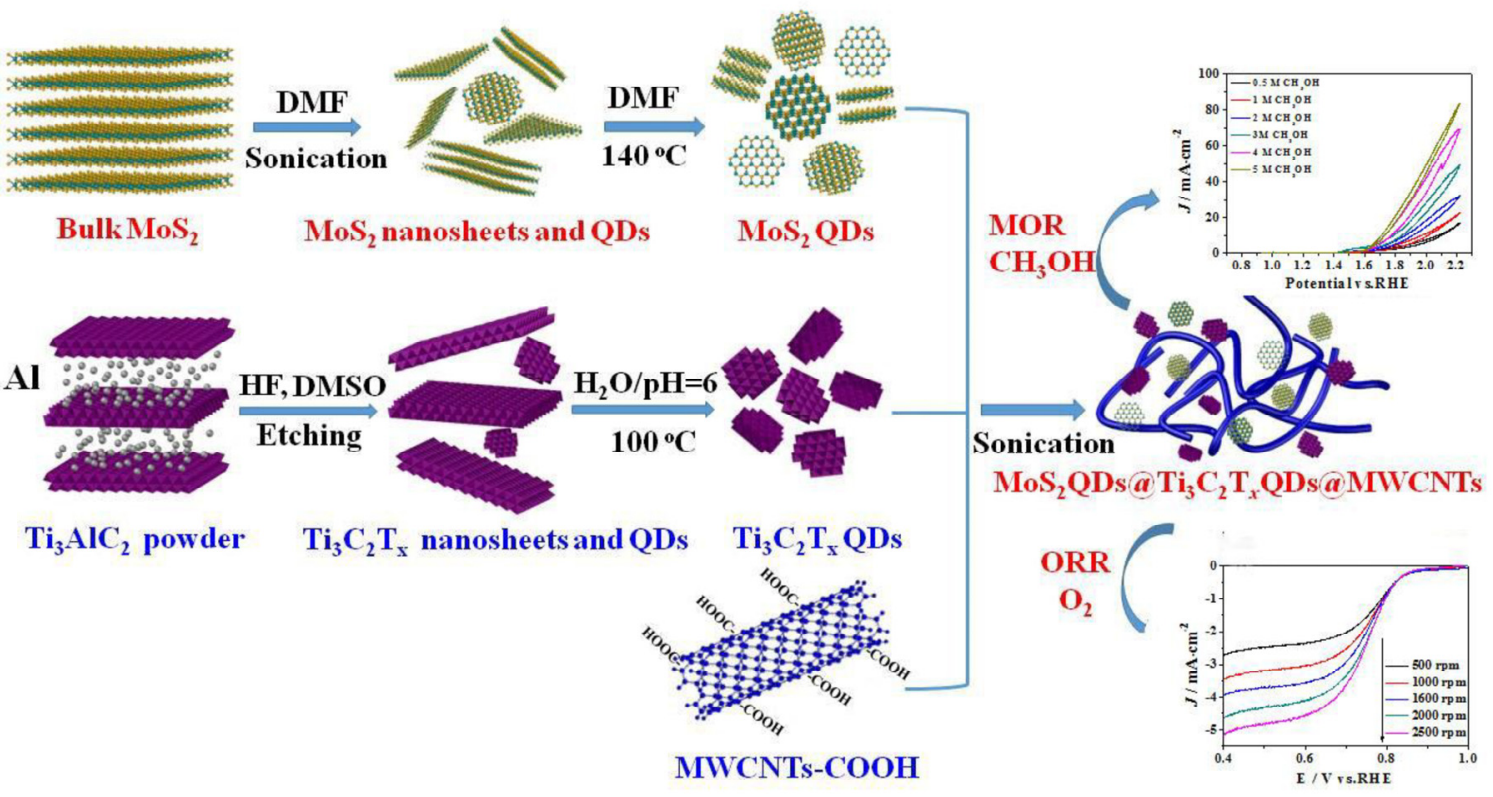

Figure 10. $\mathrm{MoS}_{2} \mathrm{QDs} @ \mathrm{Ti}_{3} \mathrm{C}_{2} \mathrm{~T}_{\mathrm{x}} \mathrm{QDs} @ \mathrm{MMWCNT}$ for the methanol oxidation and oxygen reduction reactions in basic solution. Reprinted with permission from [51].

The as-prepared $\mathrm{Mn}_{3} \mathrm{O}_{4} / \mathrm{MXene}$ hybrid structure shows favorable electrochemical activity for ORR with a foremost four-electron oxygen reduction route and $\sim 0.89 \mathrm{~V}$ onset potential (similar to that of $\mathrm{Pt} / \mathrm{C}$ ) in basic solution. The metal type conductivity and hydrophilic nature help in raising the speed of electron transfer and reducing the accumulation of nanoparticles. Additionally, $\mathrm{Mn}_{3} \mathrm{O}_{4} / \mathrm{MXene}$ shows greater stability compared to $\mathrm{Mn}_{3} \mathrm{O}_{4}$ /acetylene black due to the most stable $\mathrm{Mn}_{3} \mathrm{O}_{4} / \mathrm{MXene}$ hybrid structure [175].

The prepared low-cost Fe doped MXene nanocomposites with excellent ORR behavior can be an assuring candidate as an ORR catalyst and for application in metal-air batteries, fuel cells, and some other energy storage devices.

\section{Concluding Remarks and Prospective}

Study reports on MXene have produced immense eagerness in the investigation of 2D materials. MXene, exfoliated from layered MAX phases, has obtained developing much attention in current time. These comprise the synthesis of simple MXenes; the exfoliation of novel MXenes, the investigations on 
these 2D systems, the characterization of these electronic, optical characteristics, and their potential energy storage applications. The characteristic features of MXene sheets cause them auspicious candidates as replacements to noble metal catalysts for different electrochemical reactions useful for renewable energy storage systems. This overview summarizes the novel development in research of MXene and reveals the prompt growth of the MXene research groups. The developments accomplished in groundwork and features, jointly with the discovered uses of MXene, deliver a robust impetus to furthest development in the description and application of these latest 2D materials.

All anticipate additional research attempts and improved interpretation. We are certain that this novel class of 2D materials shows very good ability, and we expect more researchers will develop this field of materials by replacing graphene and give important scientific elaborations.

Funding: The publication of this article was funded by Qatar National Library.

Acknowledgments: This work was carried by the NPRP grant \# NPRP11S-1221-170116 from the Qatar National Research Fund (a member of Qatar Foundation). The statements made herein are solely the responsibility of the authors. The publication of this article was funded by the Qatar National Library.

Conflicts of Interest: The authors declare no conflict of interest.

\section{References}

1. Tang, Q.; Zhou, Z.; Chen, Z. Graphene-related nanomaterials: Tuning properties by functionalization. Nanoscale 2013, 5, 4541-4551. [CrossRef] [PubMed]

2. Tang, Q.; Zhou, Z. Graphene-analogous low -dimensional materials. Prog. Mater. Sci. 2013, 58, $1244-1315$. [CrossRef]

3. Naguib, M.; Gogotsi, Y. Synthesis of two -dimensional materials by selective extraction. Acc. Chem. Res. 2015, 48, 128-135. [CrossRef] [PubMed]

4. Naguib, M.; Kurtoglu, M.; Presser, V.; Lu, J.; Niu, J.; Heon, M.; Hultman, L.; Gogotsi, Y.; Barsoum, M.W. Two-dimensional nanocrystals produced by exfoliation of $\mathrm{Ti}_{3} \mathrm{AlC}_{2}$. Adv. Mater. 2011, 23, 4248-4253. [CrossRef] [PubMed]

5. Shein, I.R.; Ivanovskii, A.L. Graphene-like nanocarbides and nanonitrides of d metals (MXenes): Synthesis. properties and simulation. Micro Nano Lett. 2013, 8, 59-62. [CrossRef]

6. Karlsson, L.H.; Birch, J.; Halim, J.; Barsoum, M.W.; Persson, P.O. Atomically resolved structural and chemical investigation of single MXene sheets. Nano Lett. 2015, 15, 4955-4960. [CrossRef]

7. Nicolosi, V.; Chhowalla, M.; Kanatzidis, M.G.; Strano, M.S.; Coleman, J.N. Liquid exfoliation of layered materials. Science 2013, 340, 72-75. [CrossRef]

8. Naguib, M.; Mochalin, V.N.; Barsoum, M.W.; Gogotsi, Y. 25th anniversary article: MXenes: A new family of Two-dimensional materials. Adv. Mater. 2014, 26, 992-1005. [CrossRef]

9. Sobolčiak, P.; Tanvir, A.; Sadasivuni, K.K.; Krupa, I. Piezoresistive Sensors Based on Electrospun Mats Modified by 2D Ti3C2Tx MXene. Sensors 2019, 19, 4589-4597. [CrossRef]

10. Guo, Z.; Zhou, J.; Zhu, L.; Sun, Z. MXene: A promisingphotocatalyst for water splitting. J. Mater. Chem. A 2016, 4, 11446-11452. [CrossRef]

11. Wen, M.Q.; Xiong, T.; Zang, Z.G.; Wei, W.; Tang, X.S.; Dong, F. Synthesis of $\mathrm{MoS}_{2} / \mathrm{g}_{-} \mathrm{C}_{3} \mathrm{~N}_{4}$ nanocomposites with enhanced visible-light photocatalytic activity for the removal of nitric oxide (NO). Opt. Express 2016, 24, 10205-10212. [CrossRef] [PubMed]

12. Hsiao, C.; Lee, C.; Tai, N. Biomass-derived three-dimensional carbon framework for a flexible fibrous supercapacitor and its application as a wearable smart textile. RSC Adv. 2020, 10, 6960-6972. [CrossRef]

13. Anasori, B.; Lukatskaya, M.R.; Gogotsi, Y. 2D metal carbides and nitrides (MXenes) for energy storage. Nat. Rev. Mater. 2017, 2, 16098. [CrossRef]

14. Li, R.; Zhang, L.; Shi, L.; Wang, P. MXene $\mathrm{Ti}_{3} \mathrm{C}_{2}$ : An effective 2D Light-to-Heat conversion material. ACS Nano 2017, 11, 3752-3759. [CrossRef] [PubMed]

15. Bhimanapati, G.R.; Lin, Z.; Meunier, V.; Jung, Y.; Cha, J.; Das, S.; Xiao, D.; Son, Y.; Strano, M.S.; Cooper, V.R.; et al. Recent advances in two-dimensional materials beyond Graphene. ACS Nano 2015, 9, 11509-11539. [CrossRef] [PubMed] 
16. Zhang, Z.; Li, H.; Zou, G.; Fernandez, C.; Liu, B.; Zhang, Q.; Hu, J.; Peng, Q. Self-Reduction synthesis of new MXene/Ag composites with unexpected electrocatalytic activity. ACS Sustain. Chem. Eng. 2016, 4, 6763-6771. [CrossRef]

17. Xue, Q.; Pei, Z.; Huang, Y.; Zhu, M.; Tang, Z.; Li, H.; Huang, Y.; Li, N.; Zhang, H.; Zhi, C. Mn ${ }_{3} \mathrm{O}_{4}$ nanoparticles on layer-structured $\mathrm{Ti}_{3} \mathrm{C}_{2}$ MXene towards the oxygen reduction reaction and zinc-air batteries. J. Mater. Chem. A 2017, 5, 20818-20823. [CrossRef]

18. Zhao, L.; Dong, B.; Li, S.; Zhou, L.; Lai, L.; Wang, Z.; Zhao, S.; Han, M.; Gao, K.; Lu, M.; et al. Interdiffusion reaction-assisted hybridization of two-dimensional metal-organic frameworks and $\mathrm{Ti}_{3} \mathrm{C}_{2} \mathrm{~T}_{\mathrm{x}}$ nanosheets for electrocatalytic oxygen evolution. ACS Nano 2017, 11, 5800-5807. [CrossRef]

19. Zhou, L.; Wu, F.; Yu, J.; Deng, Q.; Zhang, F.; Wang, G. Titanium carbide $\left(\mathrm{Ti}_{3} \mathrm{C}_{2} \mathrm{~T}_{\mathrm{x}}\right)$ MXene: A novel precursor to amphiphilic carbide-derived graphene quantum dots for fluorescent ink, light-emitting composite and bioimaging. Carbon 2017, 118, 50-57. [CrossRef]

20. Kota, S.; Chen, Y.; Wang, J.; May, S.J.; Radovic, M.; Barsoum, M.W. Synthesis and characterization of the atomic laminate $\mathrm{Mn}_{2} \mathrm{AlB}_{2}$. J. Eur. Ceram. Soc. 2018, 38, 5333-5340. [CrossRef]

21. Zang, X.; Wang, J.; Yijiang, Q.; Wang, T.; He, C.; Shao, Q. Enhancing Capacitance Performance of $\mathrm{Ti}_{3} \mathrm{C}_{2} \mathrm{~T}_{\mathrm{x}}$ MXene as Electrode Materials of Supercapacitor: From Controlled Preparation to Composite Structure Construction. Nano Micro Lett. 2020, 12, 77. [CrossRef]

22. Nyamdelger, S.; Ochirkhuyag, T.; Sangaa, D.; Odkhuu, D. First-principles prediction of a two-dimensional vanadium carbide (MXene) as the anode for lithium ion batteries. Phys. Chem. Chem. Phys. 2020, 22, 5807-5818. [CrossRef] [PubMed]

23. Kim, H.; Anasori, B.; Gogotsi, Y.; Alshareef, H.N. Thermoelectric properties of two dimensional molybdenum-based MXenes. Chem. Mater. 2017, 29, 6472-6479. [CrossRef]

24. Ahmed, B.; Anjum, D.H.; Hedhili, M.N.; Gogotsi, Y.; Alshareef, H.N. $\mathrm{H}_{2} \mathrm{O}_{2}$ assisted room temperature oxidation of $\mathrm{Ti}_{2} \mathrm{C}$ MXene for Li-ion battery anodes. Nanoscale 2016, 8, 7580-7587. [CrossRef]

25. Lin, Z.Y.; Sun, D.F.; Huang, Q.; Yang, J.; Barsoum, M.W.; Yan, X.B. Carbon nanofiber bridged two-dimensional titanium carbide as a superior anode for lithium-ion batteries. J. Mater. Chem. A 2015, 3, 14096-14100. [CrossRef]

26. Ren, C.E.; Zhao, M.-Q.; Makaryan, T.; Halim, J.; Boota, M.; Kota, S.; Anasori, B.; Barsoum, M.W.; Gogotsi, Y. Porous Two-Dimensional Transition Metal Carbide (MXene) Flakes for High-Performance Li-Ion Storage. ChemElectroChem 2016, 3, 689-693. [CrossRef]

27. Zhao, S.; Meng, X.; Zhu, K.; Du, F.; Chen, G.; Wei, Y.; Gogotsi, Y.; Gao, Y. Li-ion uptake and increase in interlayer spacing of $\mathrm{Nb}_{4} \mathrm{C}_{3} \mathrm{MXene.} \mathrm{Energy} \mathrm{StorageMater.} \mathrm{2017,} \mathrm{8,} \mathrm{42-48.} \mathrm{[CrossRef]}$

28. Zhao, M.-Q.; Torelli, M.; Ren, C.E.; Ghidiu, M.; Ling, Z.; Anasori, B.; Barsoum, M.W.; Gogotsi, Y. 2D titanium carbide and transition metal oxides hybrid electrodes for Li-ion storage. Nano Energy 2016, 30, 603-613. [CrossRef]

29. Ahmed, B.; Anjum, D.H.; Gogotsi, Y.; Alshareef, H.N. Atomic layer deposition of $\mathrm{SnO}_{2}$ on MXene for Li-ion battery anodes. Nano Energy 2017, 34, 249-256. [CrossRef]

30. Shen, C.; Wang, L.; Zhou, A.; Zhang, H.; Chen, Z.; Hu, Q.; Qin, G. $\mathrm{MoS}_{2}$-Decorated Ti ${ }_{3} \mathrm{C}_{2}$ MXene nanosheet as anode material in lithium-ion batteries. J. Electrochem. Soc. 2017, 164, A2654. [CrossRef]

31. Ling, Z.; Ren, C.E.; Zhao, M.-Q.; Yang, J.; Giammarco, J.M.; Qiu, J.; Barsoum, M.W.; Gogotsi, Y. Flexible and conductive MXene films and nanocomposites with high capacitance. Proc. Natl. Acad. Sci. USA 2014, 111, 16676-16681. [CrossRef] [PubMed]

32. Naguib, M.; Halim, J.; Lu, J.; Cook, K.M.; Hultman, L.; Gogotsi, Y.; Barsoum, M.W. New two-dimensional niobium and vanadium carbides as promising materials for li-ion batteries. J. Am. Chem. Soc. 2013, 135, 15966-15969. [CrossRef] [PubMed]

33. Chang, F.; Li, C.; Yang, J.; Tang, H.; Xue, M. Synthesis of a new graphene-like transition metal carbide by deintercalating $\mathrm{Ti}_{3} \mathrm{AlC}_{2}$. Mater. Lett. 2013, 109, 295-298. [CrossRef]

34. Naguib, M.; Mashtalir, O.; Carle, J.; Presser, V.; Lu, J.; Hultman, L.; Gogotsi, Y.; Barsoum, M.W. Two-dimensional transition metal carbides. ACS Nano 2012, 6, 1322-1331. [CrossRef]

35. Halim, J.; Lukatskaya, M.R.; Cook, K.M.; Lu, J.; Smith, C.R.; Naslund, L.A.; May, S.J.; Hultman, L.; Gogotsi, Y.; Eklund, P.; et al. Transparent conductive two dimensional titanium carbide epitaxial thin films. Chem. Mater. 2014, 26, 2374-2381. [CrossRef] 
36. Ghidiu, M.; Naguib, M.; Shi, C.; Mashtalir, O.; Pan, L.M.; Zhang, B.; Yang, J.; Gogotsi, Y.; Billinge, S.J.L.; Barsoum, M.W. Synthesis and characterization of two-dimensional $\mathrm{Nb}_{4} \mathrm{C}_{3}$ (MXene). Chem. Commun. 2014, 50, 9517-9520. [CrossRef]

37. Feng, Y.; Deng, Q.; Peng, C.; Hu, J.; Li, Y.; Wu, Q.; Xu, Z. An ultrahigh discharged energy density achieved in an inhomogeneous PVDF dielectric composite filled with 2D MXene nanosheets via interface engineering. J. Mater. Chem. C 2018, 6, 13283-13292. [CrossRef]

38. Ghidiu, M.; Lukatskaya, M.R.; Zhao, M.Q.; Gogotsi, Y.; Barsoum, M.W. Conductive two-dimensional titanium carbide 'clay' with high volumetric capacitance. Nature 2014, 516, 78-81. [CrossRef]

39. Persson, I.; El Ghazaly, A.; Tao, Q.; Halim, J.; Kota, S.; Darakchieva, V.; Palisaitis, J.; Barsoum, M.W.; Rosen, J.; Persson, P.O.Å. Tailoring structure, composition, and energy storage properties of MXenes from selective etching of in-plane, chemically orderedMAX phases. Small 2018, 1703676, 1-7.

40. Tu, S.; Jiang, Q.; Zhang, J.; He, X.; Hedhili, M.N.; Zhang, X.; Alshareef, H.N. Enhancement of Dielectric Permittivity of $\mathrm{Ti}_{3} \mathrm{C}_{2} \mathrm{~T}_{x}$ MXene/Polymer Composites by Controlling Flake Size and Surface Termination. ACS Appl. Mater. Interfaces 2019, 30, 27358-27362. [CrossRef]

41. Tu, S.; Jiang, Q.; Zhang, X.; Husam Alshareef, N. Large Dielectric Constant Enhancement in MXene Percolative Polymer Composites. ACS Nano 2018, 12, 3369-3377. [CrossRef] [PubMed]

42. Johnson, M.; Zhang, Q.; Wang, D. Titanium carbide MXene: Synthesis, electrical and optical properties and their applications in sensors and energy storage devices. Nanomater. Nanotechnol. 2019, 9, 1-12. [CrossRef]

43. Seyedin, S.; Yanza, E.R.S.; Razal, J.M. Knittable energy storing fiber with high volumetric performance made from predominantly MXene nanosheets. J. Mater. Chem. A 2017, 5, 24076-24082. [CrossRef]

44. Yang, Q.; Xu, Z.; Fang, B.; Huang, T.; Cai, S.; Chen, H.; Liu, Y.; Gopalsamy, K.; Gao, W.; Gao, C. MXene/graphene hybrid fibers for high performance flexible supercapacitors. J. Mater. Chem. A 2017, 5, 22113-22119. [CrossRef]

45. Li, H.; Hou, Y.; Wang, F.; Lohe, M.R.; Zhuang, X.; Niu, L.; Feng, X. Flexible all-solid-state supercapacitors with high volumetric capacitances boosted by solution processable MXene and electrochemically exfoliated graphene. Adv. Energy Mater. 2017, 7, 1601847. [CrossRef]

46. Xiao, Y.; Zhang, W. High-Throughput Calculation Investigations on the Electrocatalytic Activity of Codoped Single Metal-Nitrogen Embedded in Graphene for ORR Mechanism. Electrocatalysis 2020. [CrossRef]

47. Lin, H.; Chen, L.; Lu, X.; Yao, H.; Chen, Y.; Shi, J. Two-dimensional titanium carbide MXenes as efficient non-noble metal electrocatalysts for oxygen reduction reaction. Sci. China Mater. 2019, 62, 662-670. [CrossRef]

48. Zeng, Z.; Yan, Y.; Chen, J.; Zan, P.; Tian, Q.; Chen, P. Boosting the Photocatalytic Ability of $\mathrm{Cu}_{2} \mathrm{O}$ Nanowires for $\mathrm{CO}_{2}$ Conversion by MXene Quantum Dots. Adv. Funct. Mater. 2018, 1806500. [CrossRef]

49. Wang, K.; Li, Q.; Liu, B.S.; Cheng, B.; Ho, W.K.; Yu, J.G. Sulfur-doped g $-\mathrm{C}_{3} \mathrm{~N}_{4}$ with enhanced photocatalytic $\mathrm{CO}_{2}$-reduction performance. Appl. Catal. B 2015, 176, 44-52. [CrossRef]

50. Zhao, H.; Lv, J.; Sang, J.; Zhu, L.; Zheng, P.; Andrew, G.; Tan, L. A Facile Method to Construct MXene/CuO Nanocomposite with Enhanced Catalytic Activity of $\mathrm{CuO}$ on Thermal Decomposition of Ammonium Perchlorate. Materials 2018, 11, 2457. [CrossRef]

51. Yang, X.; Jia, Q.; Duan, F.; Hu, B.; Wang, M.; He, L.; Song, Y.; Zhang, Z. Multiwall carbonnanotubes loaded with $\mathrm{MoS}_{2}$ quantum dots and MXene quantum dots: Non-Pt bifunctional catalyst for the methanol oxidation and oxygen reduction reactions in alkaline solution. Appl. Surf. Sci. 2017, 464, 78-87. [CrossRef]

52. Yu, X.; Yin, W.; Wang, T.; Zhang, Y. Decorating g- $\mathrm{C}_{3} \mathrm{~N}_{4}$ Nanosheets with $\mathrm{Ti}_{3} \mathrm{C}_{2}$ MXene Nanoparticles for Efficient Oxygen Reduction Reaction. Langmuir 2019, 35, 2909-2916. [CrossRef] [PubMed]

53. Mashtalir, O.; Naguib, M.; Mochalin, V.N.; Dall'Agnese, Y.; Heon, M.; Barsoum, M.W.; Gogotsi, Y. Intercalation and delamination of layered carbides and carbonitrides. Nat. Commun. 2013, 4, 1716. [CrossRef] [PubMed]

54. Wang, K.; Zhou, Y.; Xu, W.; Huang, D.; Wang, Z.; Hong, M. Fabrication and thermal stability of two-dimensional carbide $\mathrm{Ti}_{3} \mathrm{C}_{2}$ nanosheets. Ceram. Int. 2016, 42, 8419-8424. [CrossRef]

55. Khazaei, M.; Arai, M.; Sasaki, T.; Estili, M.; Sakka, Y. Two-dimensional molybdenum carbides: Potential thermoelectric materials of the MXene family. Phys. Chem. Chem. Phys. 2014, 16, 7841-7849. [CrossRef] [PubMed]

56. Zha, X.H.; Yin, J.; Zhou, Y.; Huang, Q.; Luo, K.; Lang, J.; Francisco, J.S.; He, J.; Du, S. Intrinsic structural, electrical, thermal and mechanicalproperties of the promising conductor $\mathrm{Mo}_{2} \mathrm{C}$ MXene. J. Phys. Chem. C 2016, 120, 15082-15088. [CrossRef] 
57. Wang, H.; Wu, Y.; Zhang, J.; Li, G.; Huang, H.; Zhang, X.; Jiang, Q. Enhancement of the electrical properties of MXene $\mathrm{Ti}_{3} \mathrm{C}_{2}$ nanosheets by post-treatments of alkalization and calcination. Mater. Lett. 2015, 160, 537-540. [CrossRef]

58. Zhang, C.J.; Anasori, B.; Seral-ascaso, A.; Park, S.; Mcevoy, N.; Shmeliov, A.; Duesberg, G.S.; Coleman, J.N.; Gogotsi, Y.; Nicolosi, V. Transparent, flexible and conductive2D titanium carbide (MXene) films with high volumetric capacitance. Adv. Mater. 2017, 29, 1702678. [CrossRef]

59. Maleski, K.; Ren, C.E.; Zhao, M.; Anasori, B.; Gogotsi, Y. Size-dependent physical and electrochemical properties of two-dimensional MXene flakes. ACS Appl. Mater. Interfaces 2018, 10, 24491-24498. [CrossRef]

60. Muckley, E.S.; Naguib, M.; Ivanov, I.N. Multi-modal, ultrasensitive, wide-range humidity sensing with $\mathrm{Ti}_{3} \mathrm{C}_{2}$ film. Nanoscale 2018, 10, 21689-21695. [CrossRef]

61. Muckley, E.S.; Naguib, M.; Wang, H.W.; Vlcek, L.; Osti, N.C.; Sacci, R.L.; Sang, X.; Unocic, R.R.; Xie, Y.; Tyagi, M.; et al. Multimodality of structural, electrical and gravimetricresponses of intercalated MXenes to water. ACS Nano 2017, 11, 11118-11126. [CrossRef] [PubMed]

62. Hantanasirisakul, K.; Gogotsi, Y. Electronic and optical properties of 2D transition metal carbides and nitrides (MXenes). Adv. Mater. 2018, 30, 1804779. [CrossRef] [PubMed]

63. Yan, J.; Ren, C.E.; Maleski, K.; Hatter, C.B.; Anasori, B.; Urbankowski, P.; Sarycheva, A.; Gogotsi, Y. Flexible MXene/graphene films for ultrafast supercapacitors with outstanding volumetric capacitance. Adv. Funct. Mater. 2017, 27, 1701264. [CrossRef]

64. He, J.; Liu, S.; Deng, L.; Shan, D.; Cao, C.; Luo, H.; Yan, S. Tunable electromagnetic and enhanced microwave absorption properties in $\mathrm{CoFe}_{2} \mathrm{O}_{4}$ decorated $\mathrm{Ti}_{3} \mathrm{C}_{2}$ MXene composites. Appl. Surf. Sci. 2020, 504, 144210. [CrossRef]

65. Tariq, A.; Ali, S.I.; Akinwande, D.; Rizwan, S. Efficient Visible-Light Photocatalysis of 2D-MXene Nanohybrids with $\mathrm{Gd}^{3+}$ and $\mathrm{Sn}^{4+}$-Codoped Bismuth Ferrite. ACS Omega 2018, 3, 13828-13836. [CrossRef] [PubMed]

66. Lee Ying, G.; Kota, S.; Dillon, A.D.; Fafarman, A.T.; Barsoum, M.W. Conductive transparent $\mathrm{V}_{2} \mathrm{CT}_{\mathrm{x}}(\mathrm{MXene})$ films. FlatChem. 2018, 8, 25-30. [CrossRef]

67. Hantanasirisakul, K.; Zhao, M.Q.; Urbankowski, P.; Halim, J.; Anasori, B.; Kota, S.; Ren, C.E.; Barsoum, M.W.; Gogotsi, Y. Fabrication of $\mathrm{Ti}_{3} \mathrm{C}_{2} \mathrm{~T}_{\mathrm{x}}$ MXene transparent thin films with tunable optoelectronic properties. Adv. Electron. Mater. 2016, 2, 1600050. [CrossRef]

68. Karthik, K.; Pushpa, S.; Madhukara Naik, M.; Vinuth, M. Influence of Sn and Mn on structural, optical and magnetic properties of spray pyrolysed CdS thin films. Mater. Res. Innovation. 2020, 24, 82-86. [CrossRef]

69. Xing, C.; Chen, S.; Liang, X.; Liu, Q.; Qu, M.; Zou, Q.; Li, J.; Tan, H.; Liu, L.; Fan, D.; et al. Two-Dimensional MXene $\left(\mathrm{Ti}_{3} \mathrm{C}_{2}\right)$-integrated cellulose hydrogels: Toward smart three-dimensional network nanoplatforms exhibiting light-induced swelling and bimodal photothermal/chemotherapy anticancer activity. ACS Appl. Mater. Interfaces 2018, 10, 27631-27643. [CrossRef]

70. Berdiyorov, G.R. Optical properties of functionalized $\mathrm{Ti}_{3} \mathrm{C}_{2} \mathrm{~T}_{2}(\mathrm{~T}=\mathrm{F}, \mathrm{O}, \mathrm{OH}) \mathrm{MXene}$ : First-principles calculations. AIP Adv. 2016, 6, 055105. [CrossRef]

71. Huang, K.; Li, Z.; Lin, J.; Han, G.; Huang, P. Two-dimensional transition metal carbides and nitrides (MXenes) for biomedical applications. Chem. Soc. Rev. 2018, 47, 5109-5124. [CrossRef] [PubMed]

72. Tang, H.; Hu, Q.; Zheng, M.; Chi, Y.; Qin, X.; Pang, H.; Xu, Q. MXene 2D layered electrode materials for energy storage. Prog. Nat. Sci. Mater. Int. 2018, 28, 133-147. [CrossRef]

73. Sun, X.; Liu, Y.; Zhang, J.; Hou, L.; Sun, J.; Yuan, C. Facile construction of ultrathin $\mathrm{SnO}_{\mathrm{x}}$ nanosheets decorated MXene $\left(\mathrm{Ti}_{3} \mathrm{C}_{2}\right)$ nanocomposite towards Li-ion batteries as high performance anode materials. Electrochim. Acta 2019, 295, 237-245. [CrossRef]

74. Pang, J.; Mendes, R.G.; Bachmatiuk, A.; Zhao, L.; Ta, H.Q.; Gemming, T.; Liu, H.; Liu, Z.; Rummeli, M.H. Applications of 2D MXenes in energy conversion and storage systems. Chem. Soc. Rev. 2018, 48, 72-133. [CrossRef] [PubMed]

75. Tang, X.; Guo, X.; Wu, W.; Wang, G. 2D metal carbides and nitrides (MXenes) as high-performance electrode materials for lithium-based batteries. Adv. Energy Mater. 2018, 8, 1801897. [CrossRef]

76. Naguib, M.; Come, J.; Dyatkin, B.; Presser, V.; Taberna, P.L.; Simon, P.; Barsoum, M.W.; Gogotsi, Y. MXene: A promisingtransition metal carbide anode for lithium-ion batteries. Electrochem. Commun. 2012, 16, 61-64. [CrossRef] 
77. Tang, Q.; Zhou, Z.; Shen, P.W. Are MXenes promising anode materials for Li ion batteries? Computational studies on electronic properties and $\mathrm{Li}$ storage capability of $\mathrm{Ti}_{3} \mathrm{C}_{2}$ and $\mathrm{Ti}_{3} \mathrm{C}_{2} \mathrm{X}_{2}(\mathrm{X}=\mathrm{F}, \mathrm{OH})$ monolayer. J. Am. Chem. Soc. 2012, 134, 16909-16916. [CrossRef]

78. Xie, Y.; Naguib, M.; Mochalin, V.N.; Barsoum, M.W.; Gogotsi, Y.; Yu, X.Q.; Nam, K.W.; Yang, X.Q.; Kolesnikov, A.I.; Kent, P.R.C. Role of surface structure on li-ion energy storage capacity of two-dimensional transition-metal carbides. J. Am. Chem. Soc. 2014, 136, 6385-6394. [CrossRef]

79. Xie, Y.; Dall'Agnese, Y.; Naguib, M.; Gogotsi, Y.; Barsoum, M.W.; Zhuang, H.L.; Kent, P.R.C. Prediction and characterization of MXene nanosheet anodes for nonlithium- ion batteries. ACS Nano 2014, 8, 9606-9615. [CrossRef]

80. Eames Islam, C.M.S. Ion intercalation into two dimensional transition-metal carbides: Global screening for new high-capacity battery materials. J. Am. Chem. Soc. 2014, 136, 16270-16276. [CrossRef]

81. Burke, A. R\&D considerations for the performance and application of electrochemical capacitors. Electrochim. Acta 2007, 53, 1083-1091.

82. Xie, X.; Zhao, M.Q.; Anasori, B.; Maleski, K.; Ren, C.E.; Li, J.; Byles, B.W.; Pomerantseva, E.; Wang, G.; Gogotsi, Y. Porous heterostructured MXene/carbon nanotube composite paper with high volumetric capacity for sodium-based energy storage devices. Nano Energy 2016, 26, 513-523. [CrossRef]

83. Bao, W.; Tang, X.; Guo, X.; Choi, S.; Wang, C.; Gogotsi, Y.; Wang, G. Porous cryo-dried MXene for efficient capacitive deionization. Joule 2018, 2, 778-787. [CrossRef]

84. Yu, Y.X. Prediction of mobility, enhanced storagecapacity and volumechange during sodiation on interlayer-expanded functionalized $\mathrm{Ti}_{3} \mathrm{C}_{2} \mathrm{MXene}$ anode materials for sodium-ion batteries. J. Phys. Chem. C 2016, 120, 5288-5296. [CrossRef]

85. Bao, W.; Xie, X.; Xu, J.; Guo, X.; Song, J.; Wu, W.; Su, D.; Wang, G. Confined sulfur in 3D MXene/reduced graphene oxide hybrid nanosheets for lithium-sulfur battery. Chem. A Eur. J. 2017, 23, 12613-12619. [CrossRef]

86. Yan, B.; Lu, C.; Zhang, P.; Chen, J.; He, W.; Tian, W.; Zhang, W.; Sun, Z.M. Oxygen/sulfur decorated 2D MXene $\mathrm{V}_{2} \mathrm{C}$ for promising lithium ion battery anodes. Mater. Today Commun. 2020, 22, 100713. [CrossRef]

87. Illa, M.P.; Khandelwal, M.; Sharma, C.S. Bacterial cellulose-derived carbon nanofibers as anode for lithium-ion batteries. Emerg. Mater. 2018, 1, 105-120. [CrossRef]

88. Mashtalir, O.; Lukatskaya, M.R.; Zhao, M.-Q.; Barsoum, M.W.; Gogotsi, Y. Amine-Assisted Delamination of $\mathrm{Nb}_{2} \mathrm{C}$ MXene for Li-Ion Energy Storage Devices. Adv. Mater. 2015, 27, 3501-3506. [CrossRef]

89. Luo, J.; Tao, X.; Zhang, J.; Xia, Y.; Huang, H.; Zhang, L.; Gan, Y.; Liang, C.; Zhang, W. Sn ${ }^{4+}$ Ion Decorated Highly Conductive $\mathrm{Ti}_{3} \mathrm{C}_{2}$ MXene: Promising Lithium-Ion Anodes with Enhanced Volumetric Capacity and Cyclic Performance. ACS Nano 2016, 10, 2491-2499. [CrossRef]

90. Zou, G.; Zhang, Z.; Guo, J.; Liu, B.; Zhang, Q.; Fernandez, C.; Peng, Q. Synthesis of MXene/Ag composites for extraordinary long cycle lifetime lithium storage at high rates. ACS Appl. Mater. Interfaces 2016, 8, 22280-22286. [CrossRef]

91. Pan, X.; Shinde, N.M.; Lee, M.; Kim, D.; Ho Kim, K.; Kang, M. Controlled nanosheet morphology of titanium carbide $\mathrm{Ti}_{3} \mathrm{C}_{2} \mathrm{~T}_{\mathrm{x}}$ MXene via drying methods and its electrochemical analysis. J. Solid State Electrochem. 2020, 24, 675-686. [CrossRef]

92. Lukatskaya, M.R.; Mashtalir, O.; Ren, C.E.; Dall'Agnese, Y.; Rozier, P.; Taberna, P.L.; Naguib, M.; Simon, P.; Barsoum, M.W.; Gogotsi, Y. Cation intercalation and high volumetric capacitance of two-dimensional titanium carbide. Science 2013, 341, 1502-1505. [CrossRef] [PubMed]

93. Syamsai, R.; Kollu, P.; Kwan Jeong, S.A. Nirmala Grace. Synthesis andproperties of 2D-titanium carbide MXene sheets towards electrochemical energy storage applications. Ceram. Int. 2017, 43, 13119-13126. [CrossRef]

94. Okubo, M.; Sugahara, A.; Kajiyama, S.; Yamada, A. MXene as a charge storage host. Acc. Chem. Res. 2018, 51, 591-599. [CrossRef]

95. Bak, S.M.; Qiao, R.; Yang, W.; Lee, S.; Yu, X.; Anasori, B.; Lee, H.; Gogotsi, Y.; Yang, X.Q. Na-ion intercalation and charge storage mechanism in 2D vanadium carbide. Adv. Energy Mater. 2017, 7, 1700959. [CrossRef]

96. Zhan, C.; Naguib, M.; Lukatskaya, M.; Kent, P.R.C.; Gogotsi, Y.; Jiang, D. Understanding the MXene pseudocapacitance. J. Phys. Chem. Lett. 2018, 9, 1223-1228. [CrossRef]

97. Weiming, W.; Changsong, Z.; Shaogang, H.; Shubin, Y. Synthesis of MXenes and MXenes-containing composites for energy storage and conversions. Chin. J. Appl. Chem. 2018, 35, 317-327. 
98. Xia, Q.X.; Fu, J.; Yun, J.M.; Mane, R.S.; Kim, K.H. High volumetric energy density annealed-MXene-nickel oxide/MXene asymmetric supercapacitor. RSC Adv. 2017, 7, 11000-11011. [CrossRef]

99. Chang H, Q.; Zhang, G.H.; Chou K, C. Topochemical synthesis of two-dimensional molybdenum carbide $\left(\mathrm{Mo}_{2} \mathrm{C}\right)$ via $\mathrm{Na}_{2} \mathrm{CO}_{3}$-Assited carbothermal reduction of $2 \mathrm{H}-\mathrm{MoS}_{2}$. Mater. Chem. Phys. 2020, 244, 122713. [CrossRef]

100. Tao, Q.; Dahlqvist, M.; Lu, J.; Kota, S.; Meshkian, R.; Halim, J.; Palisaitis, J.; Hultman, L.; Barsoum, M.W.; Persson, P.O.Å.; et al. Two-dimensional Mo ${ }_{1.33} \mathrm{C}$ MXene with divacancy ordering prepared from parent 3D laminate with in-plane chemical ordering. Nat. Commun. 2017, 8, 14949. [CrossRef]

101. Xin, Y.; Yu, Y.X. Possibility of bare and functionalized niobium carbide MXenes for electrode materials of supercapacitors and field emitters. Mater. Des. 2017, 130, 512-520. [CrossRef]

102. He, X.; Bai, Y.; Zhu, C.; Sun, Y.; Li, M.; Barsoum, M.W. General trends in the structural, electronic andelastic properties of the $\mathrm{M}_{3} \mathrm{AlC}_{2}$ phases $(\mathrm{M}=$ transition metal): A first-principle study. Comput. Mater. Sci. 2010, 49, 691-698. [CrossRef]

103. Kayali, E.; Vahidmohammadi, A.; Orangi, J.; Beidaghi, M. Controlling the dimensions of 2D MXenes for ultrahigh-rate pseudocapacitive energy storage. ACS Appl. Mater. Interfaces 2018, 10, 25949-25954. [CrossRef] [PubMed]

104. Ran, F.; Wang, T.; Chen, S.; Liu, Y.; Shao, L. Constructing expanded ion transport channels in flexible MXene film for pseudocapacitive energy storage. Appl. Surf. Sci. 2020, 511, 145627. [CrossRef]

105. Zhang, C.; Xu, S.; Cai, D.; Cao, J.; Wang, L.; Han, W. Planar supercapacitor with high areal capacitance based on Ti3C2/Polypyrrole composite film. Electrochimica Acta 2020, 330, 135277. [CrossRef]

106. Shan, Q.; Mu, X.; Alhabeb, M.; Shuck, C.E.; Pang, D.; Zhao, X.; Chu, X.F.; Wei, Y.; Du, F.; Chen, G.; et al. Two-dimensional vanadium carbide $\left(\mathrm{V}_{2} \mathrm{C}\right)$ MXene as electrode for supercapacitors with aqueous electrolytes. Electrochem. Commun. 2018, 96, 103-107. [CrossRef]

107. Anasori, B.; Xie, Y.; Beidaghi, M.; Lu, J.; Hosler, B.C.; Hultman, L.; Kent, P.R.C.; Gogotsi, Y.; Barsoum, M.W. Two-dimensional, ordered double transitionmetals carbides (MXenes). ACS Nano 2015, 9, 9507-9516. [CrossRef]

108. Halim, J.; Kota, S.; Lukatskaya, M.R.; Naguib, M.; Zhao, M.Q.; Moon, E.J.; Pitock, J.; Nanda, J.; May, S.J.; Gogotsi, Y.; et al. Synthesis and characterization of 2D molybdenum carbide (MXene). Adv. Funct. Mater. 2016, 26, 3118-3127. [CrossRef]

109. Boota, T.M.; Anasori, B.; Voigt, C.; Zhao, M.; Barsoum, M.W.; Gogotsi, Y. Pseudocapacitive electrodes produced by oxidant-free polymerization of pyrrole between the layers of 2D titanium carbide (MXene). Adv. Mater. 2015, 28, 1517-1522. [CrossRef]

110. Liu, P.; Yao, Z.; Ng, V.M.H.; Zhou, J.; Kong, L.B.; Yue, K. Facile synthesis of ultrasmall $\mathrm{Fe}_{3} \mathrm{O}_{4}$ nanoparticles on MXenes for high microwave absorption performance. Compos. Part A 2018, 115, 371-382. [CrossRef]

111. Sobolčiak, P.; Ali, A.; Hassan, M.K.; Helal, M.I.; Tanvir, A.; Popelka, A. $2 \mathrm{D} \mathrm{Ti}_{3} \mathrm{C}_{2} \mathrm{~T}_{\mathrm{x}}$ (MXene)-reinforced polyvinyl alcohol (PVA) nanofibers with enhanced mechanical and electrical properties. PLoS ONE 2017, 12, e0183705. [CrossRef]

112. Kunkel, C.; Viñes, F.; Illas, F. Transition metal carbides as novel materials for $\mathrm{CO}_{2}$ capture, storage and activation. Energy Environ. Sci. 2016, 9, 141-144. [CrossRef]

113. Reuter, K. Modelling and Simulation of Heterogeneous Catalytic Reactions; Wiley-VCH Verlag GmbH \& Co. KGaA: Hoboken, NJ, USA, 2011; Chapter 3.

114. Morales-García, Á.; Fernández-Fernández, A.; Viñes, F.; Illas, F. $\mathrm{CO}_{2}$ abatement using two-dimensional MXene carbides. J. Mater. Chem. A 2018, 6, 3381-3385. [CrossRef]

115. Shah, S.; Shah, M.; Shah, A. Evolution in the membrane-based materials and comprehensive review on carbon capture and storage in industries. Emerg. Mater. 2020. [CrossRef]

116. Singh, G.; Tiburcius, S.; Ruban, S.M.; Shanbhag, D.; Sathish, C.I.; Ramadass, K.; Vinu, A. Pure and strontium carbonate nanoparticles functionalized microporous carbons with high specific surface areas derived from chitosan for $\mathrm{CO}_{2}$ adsorption. Emerg. Mater. 2019, 2, 337-349. [CrossRef]

117. Zhou, S.; Liu, Y.; Li, J.; Wang, Y.; Jiang, G.; Zhao, Z.; Wei, Y. Facile in situ synthesis of graphitic carbon nitride $\left(\mathrm{g}-\mathrm{C}_{3} \mathrm{~N}_{4}\right)-\mathrm{N}-\mathrm{TiO}_{2}$ heterojunction as an efficient photocatalyst for the selective photoreduction of $\mathrm{CO}_{2}$ to $\mathrm{CO}$. Appl. Catal. B Environ. 2014, 158-159, 20-29. [CrossRef] 
118. Peng, Q.; Guo, J.; Zhang, Q.; Xiang, J.; Liu, B.; Zhou, A.; Liu, R.; Tian, Y. Unique Lead Adsorption Behavior of Activated Hydroxyl Group in Two-Dimensional Titanium Carbide. J. Am. Chem. Soc. 2014, 136, 4113-4116. [CrossRef]

119. Liu, Y.; Kelly, T.G.; Chen, J.G.; Mustain, W.E. Metal Carbides as Alternative Electrocatalysts Supports. ACS Catal. 2013, 3, 1184-1194. [CrossRef]

120. Chen, W.F.; Wang, C.H.; Sasaki, K.; Marinkovic, N.; Xu, W.; Muckerman, J.T.; Zhu, Y.; Adzic, R.R. Highly Active and Durable Nanostructured Molybdenum Carbide Electrocatalysts for Hydrogen Production. Energy Environ. Sci. 2013, 6, 943-951. [CrossRef]

121. Lee, J.S. Metal Carbides. In Encyclopedia of Catalysis; John Wiley \& Sons, Inc.: Hoboken, NJ, USA, 2002.

122. Hong, S.; Kyun Rhee, C.; Sohn, Y. Photoelectrochemical hydrogen evolution and $\mathrm{CO}_{2}$ reduction over $\mathrm{MoS}_{2} / \mathrm{Si}$ and $\mathrm{MoSe}_{2} / \mathrm{Si}$ nanostructures by combined photoelectrochemical deposition and rapid thermal annealing process. Catalysis 2019, 9, 494-505. [CrossRef]

123. Avila-Bolivar, B.; Garcia-Cruz, L.; Montiel, V.; Solla-Gullon, J. Electrochemical reduction of $\mathrm{CO}_{2}$ to formate on easily prepared carbon-supported Bi nanoparticles. Molecules 2019, 24, 2032-2046. [CrossRef] [PubMed]

124. Hiragond, C.B.; Kim, H.; Lee, J.; Sorcar, S.; Erkey, C.; In, S.I. Electrochemical $\mathrm{CO}_{2}$ reduction to $\mathrm{CO}$ catalysed by 2D nanostructures. Catalysts 2020, 10, 98. [CrossRef]

125. Kumaravel, V.; John, B.; Pillai, S.C. Photoelectrochemical Conversion of Carbon Dioxide $\left(\mathrm{CO}_{2}\right)$ into Fuels and Value-Added Products. ACS Energy Lett. 2020, 5, 486-519. [CrossRef]

126. Xia, T.; Long, R.; Gao, C.; Xiong, Y. Design of atomically dispersed catalytic sites for photocatalytic $\mathrm{CO}_{2}$ reduction. Nanoscale 2019, 11, 11064-11070. [CrossRef] [PubMed]

127. Chen, J.; Yin, J.; Zheng, X.; Ait Ahsaine, H.; Zhou, Y.; Dong, C.; Mohammed, O.F.; Takanabe, K.; Bakr, O.M. Compositionally Screened Eutectic Catalytic Coatings on Halide Perovskite Photocathode for Photo-Assisted Selective $\mathrm{CO}_{2}$ Reduction. ACS Energy Lett. 2019, 4, 1279-1286. [CrossRef]

128. Low, J.; Zhang, L.; Tong, T.; Shen, B.; Yu, J. TiO 2 /MXene $\mathrm{Ti}_{3} \mathrm{C}_{2}$ composite with excellent photocatalytic $\mathrm{CO}_{2}$ reduction activity. J. Catal. 2018, 361, 255-266. [CrossRef]

129. Zubair, M.; Kim, H.; Razzaq, A.; Grimes, C.A.; In, S.I. Solar spectrum photocatalytic conversion of $\mathrm{CO}_{2}$ to $\mathrm{CH}_{4}$ utilizing $\mathrm{TiO}_{2}$ nanotube arrays embedded with graphene quantum dots. J. $\mathrm{CO}_{2}$ Util. 2018, 26, 70-79. [CrossRef]

130. Razzaq, A.; Grimes, C.A.; In, S.I. Facile fabrication of a noble metal-free photocatalyst: $\mathrm{TiO}_{2}$ nanotube arrays covered with reduced graphene oxide. Carbon 2016, 98, 537-544. [CrossRef]

131. Wang, T.; Meng, X.G.; Liu, G.G.; Chang, K.; Li, P.; Kang, Q.; Liu, L.Q.; Li, M.; Ouyang, S.X.; Ye, J.H. In situ synthesis of ordered mesoporous $\mathrm{Co}$-doped $\mathrm{TiO}_{2}$ and its enhanced photocatalytic activity and selectivity for the reduction of $\mathrm{CO}_{2}$. J. Mater. Chem. A 2015, 3, 9491-9501. [CrossRef]

132. Manzanares, M.; Fabrega, C.; Osso, J.O.; Vega, L.F.; Andreu, T.; Morante, J.R. Engineering the TiO 2 outermost layers using magnesium for carbon dioxide photoreduction. Appl. Catal. B 2014, 150, 57-62. [CrossRef]

133. Adekoya, D.O.; Tahir, M.; Amin, N.A.S. g-C3N4/(Cu/TiO2) nanocomposite for enhanced photoreduction of $\mathrm{CO}_{2}$ to $\mathrm{CH}_{3} \mathrm{OH}$ and $\mathrm{HCOOH}$ under UV/visible light. J. $\mathrm{CO}_{2}$ Util. 2017, 18, 261-274. [CrossRef]

134. Shi, H.; Long, S.; Hu, S.; Hou, J.; Ni, W.; Song, C.; Li, K.; Gurzadyan, G.G.; Guo, X. Interfacial charge transfer in 0D/2D defect-rich heterostructures for efficient solar-driven $\mathrm{CO}_{2}$ reduction. Appl. Catal. B Environ. 2019, 245, 760-769. [CrossRef]

135. Yang, J.; Wen, Z.; Shen, X.; Dai, J.; Li, Y.; Li, Y. A comparative study on the photocatalytic behavior of graphene- $\mathrm{TiO}_{2}$ nanostructures: Effect of $\mathrm{TiO}_{2}$ dimensionality on interfacial charge transfer. Chem. Eng. J. 2018, 334, 907-921. [CrossRef]

136. Li, N.; Chen, X.; Ong, W.J.; MacFarlane, D.R.; Zhao, X.; Cheetham, A.K.; Sun, C. Understanding of Electrochemical Mechanisms for $\mathrm{CO}_{2}$ Capture and Conversion into Hydrocarbon Fuels in Transition-Metal Carbides (MXenes). ACS Nano 2017, 11, 10825-10833. [CrossRef] [PubMed]

137. Chen, H.; Handoko, A.D.; Xiao, J.; Feng, X.; Fan, Y.; Wang, T.; Zhang, Q. Catalytic effect on $\mathrm{CO}_{2}$ electroreduction by hydroxyl-terminated two-dimensional MXenes. ACS Appl. Mater. Interfaces 2019, 11, 36571-36579. [CrossRef]

138. Yuan, H.; Li, Z.; Yang, J. Transition-metal diboride: A new family of two-dimensional materials designed for selective $\mathrm{CO}_{2}$ electroreduction. J. Phys. Chem. C 2019, 123, 16294-16299. [CrossRef] 
139. Kumar, B.; Brian, J.P.; Atla, V.; Kumari, S.; Bertram, K.A.; White, R.T.; Spurgeon, J.M. New trends in the development of heterogenous catalyst for electrochemical $\mathrm{CO}_{2}$ reduction. Catal. Today 2016, 270, 19-30. [CrossRef]

140. Chen, Y.; Yang, K.; Jiang, B.; Li, J.; Zeng, M.; Fu, L. Emerging two-dimensional nanomaterials for electrochemical hydrogen evolution. J. Mater. Chem. A 2017, 5, 8187-8208. [CrossRef]

141. Zhang, S.; Zhuo, H.; Li, S.; Bao, Z.; Deng, S.; Zhuang, G.; Wang, J.G. Effects of surface functionalization of MXene based nanocrystals on hydrogen evolution reaction performance. Catal. Today 2020. [CrossRef]

142. Seh, Z.W.; Fredrickson, K.D.; Anasori, B.; Kibsgaard, J.; Strickler, A.L.; Lukatskaya, M.R.; Gogotsi, Y.; Jaramillo, T.F.; Vojvodic, A. Two-Dimensional Molybdenum Carbide (MXene) as an Efficient Electrocatalyst for Hydrogen Evolution. ACS Energy Lett. 2016, 1, 589-594. [CrossRef]

143. Cheng, Y.W.; Dai, J.H.; Zhang, Y.M.; Song, Y. Two-Dimensional, Ordered. Double TransitionMetal Carbides (MXenes): A New Family of Promising Catalysts for the Hydrogen Evolution Reaction. J. Phys. Chem. C 2018, 122, 28113-28122. [CrossRef]

144. Qu, G.; Zhou, Y.; Wu, T.; Zhao, G.; Li, F.; Kang, Y.; Xu, C. Phosphorized MXene-Phase Molybdenum Carbide as an Earth-Abundant Hydrogen Evolution Electrocatalyst. ACS Appl. Energy Mater. 2018, 1, 7206-7212. [CrossRef]

145. Yuan, W.; Huang, Q.; Yang, X.; Cui, Z.; Zhu, S.; Li, Z.; Du, S.; Qiu, N.; Liang, Y. Two-Dimensional Lamellar $\mathrm{Mo}_{2} \mathrm{C}$ for Electrochemical Hydrogen Production: Insights into the Origin of Hydrogen Evolution Reaction Activity in Acidic and Alkaline Electrolytes. ACS Appl. Mater. Interfaces 2018, 10, 40500-40508. [CrossRef] [PubMed]

146. Tran, M.H.; Schäfer, T.; Shahraei, A.; Dürrschnabel, M.; Molina-Luna, L.; Kramm, U.I.; Birkel, C.S. Adding a New Member to the MXene Family: Synthesis, Structure and ElectrocatalyticActivity for the Hydrogen Evolution Reaction of $\mathrm{V}_{4} \mathrm{C}_{3} \mathrm{~T}_{\mathrm{x}}$. ACS Appl. Energy Mater. 2018, 1, 3908-3914. [CrossRef]

147. Xiong, J.; Li, J.; Shi, J.; Zhang, X.; Suen, N.T.; Liu, Z.; Huang, Y.; Xu, G.; Cai, W.; Lei, X.; et al. In Situ Engineering of Double-Phase Interface in $\mathrm{Mo} / \mathrm{Mo}_{2} \mathrm{C}$ Heteronanosheets for Boosted Hydrogen Evolution Reaction. ACS Energy Lett. 2018, 3, 341-348. [CrossRef]

148. Handoko, A.D.; Fredrickson, K.D.; Anasori, B.; Convey, K.W.; Johnson, L.R.; Gogotsi, Y.; Vojvodic, A.; Seh, Z.W. Tuning the Basal Plane Functionalization of Two-Dimensional Metal Carbides (MXenes) To Control Hydrogen Evolution Activity. ACS Appl. Energy Mater. 2018, 1, 173-180. [CrossRef]

149. Liu, J.; Liu, Y.; Xu, D.; Zhu, Y.; Peng, W.; Li, Y.; Zhang, F.; Fan, X. Hierarchical "nanoroll" like $\mathrm{MoS}_{2} / \mathrm{Ti}_{3} \mathrm{C}_{2} \mathrm{~T}_{\mathrm{x}}$ hybrid with high electrocatalytic hydrogen evolution activity. Appl. Catal. B Environ. 2019, 241, 89-94. [CrossRef]

150. Zhang, J.; Zhao, Y.; Guo, X.; Chen, C.; Dong, C.L.; Liu, R.S.; Han, C.P.; Li, Y.; Gogotsi, Y.; Wang, G. Single platinum atoms immobilized on an MXene as an efficient catalyst for the hydrogen evolution reaction. Nat. Catal. 2018, 1, 985-992. [CrossRef]

151. Banham, D.; Ye, S. Current status and future development of catalyst materials and catalyst layers for proton exchange membrane fuel cells: An industrial perspective. ACS Energy Lett. 2017, 2, 629-638. [CrossRef]

152. Li, Y.; Lu, J. Metal-air batteries: Will they be the future electrochemical energy storage device of choice? ACS Energy Lett. 2017, 2, 1370-1377. [CrossRef]

153. Wang, C.; Yu, Y.; Niu, J.; Liu, Y.; Bridges, D.; Liu, X.; Hu, A. Recent progress of metal-air batteries-A mini review. Appl. Sci. 2019, 9, 2787. [CrossRef]

154. Ren, X.; Lv, Q.; Liu, L.; Liu, B.; Wang, Y.; Liu, A.; Wu, G. Current progress of pt and pt- based electrocatalysts used for fuel cells. Sustain. Energy Fuels 2020, 4, 15-30. [CrossRef]

155. Li, K.; Jiao, T.; Xing, R.; Zou, G.; Zhou, J.; Zhang, L.; Peng, Q. Fabrication of tunable hierarchical MXene@AuNPs nanocomposites constructed by self-reduction reactions with enhanced catalytic performances. Sci. China Mater. 2018, 61, 728-736. [CrossRef]

156. Murata, T.; Kotsuki, K.; Murayama, H.; Tsuji, R.; Morita, Y. Metal-free electrocatalysts for oxygen reduction reaction based on trioxotriangulene. Commun. Chem. 2019, 2, 46. [CrossRef]

157. Ma, R.; Lin, G.; Zhou, Y.; Liu, Q.; Zhang, T.; Shan, G.; Wang, J. A review of oxygen reduction mechanisms for metal-free carbon-based electrocatalysts. NPJ Comput. Mater. 2019, 5, 78. [CrossRef]

158. Zhou, S.; Yang, X.; Pei, W.; Liu, N.; Zhao, J. Heterostructures of MXene and N-doped graphene as highly active bifunctional electrocatalysts. Nanoscale 2020, 14, 10876-10883. [CrossRef] 
159. Lin, H.; Chen, Y.; Shi, J. Insights into 2D MXenes for versatile biomedical applications: Current advances and challenges ahead. Adv. Sci. 2018, 5, 1800518. [CrossRef]

160. Hussain, Z.; Ojha, R.; Martin, L.L. Controlling the morphological and redox properties of the CuTCNQ catalyst through solvent engineering. Emerg. Mater. 2019, 2, 35-44. [CrossRef]

161. Wu, Z.; Ambrožová, N.; Eftekhari, E.; Šihor, M.; Praus, P.; Svoboda, L.; Mamulová, K.K.; Kočí, K. Photocatalytic $\mathrm{H}_{2}$ generation from aqueous ammonia solution using $\mathrm{TiO}_{2}$ nanowires-intercalated reduced graphene oxide composite membrane under low power UV light. Emerg. Mater. 2019, 2, 303-311. [CrossRef]

162. Jiao, Y.; Zheng, Y.; Jaroniec, M.; Qiao, S.Z. Design of electrocatalysts for oxygen-and hydrogen-involving energy conversion reactions. Chem. Soc. Rev. 2015, 44, 2060-2086. [CrossRef]

163. Du, C.; Huang, H.; Feng, X.; Wu, S.; Song, W. Confining $\mathrm{MoS}_{2}$ nanodots in 3D porous nitrogen-doped graphene with amendable ORR performance. J. Mater. Chem. A 2015, 3, 7616-7622. [CrossRef]

164. Wang, M.; Ma, Z.; Li, R.; Tang, B.; Bao, X.; Zhang, Z.; Wang, X. Novel flower-like PdAu(Cu) anchoring on a 3D rGO-CNT sandwich-stacked framework for highly efficient methanol and ethanol electro-oxidation. Electrochim. Acta 2017, 227, 330-344. [CrossRef]

165. Li, R.; Ma, Z.; Zhang, F.; Meng, H.; Wang, M.; Bao, X.; Tang, B.; Wang, X. Facile Cur P-C hybrid supported strategy to improve $\mathrm{Pt}$ nanoparticle electrocatalytic performance toward methanol, ethanol, glycol and formic acid electro-oxidation. Electrochim. Acta 2016, 220, 193-204. [CrossRef]

166. Liu, J.; Peng, W.; Li, Y.; Fan, X. 2D MXene-Based Materials for Electrocatalysis. Trans. Tianjin Univ. 2020. [CrossRef]

167. Lei, J.; Zhang, X.; Zhou, Z. Recent advances in MXene: Preparation, properties, and applications. Front. Phys. 2015, 10, 276-286. [CrossRef]

168. Tang, Y.; Yang, C.; Tian, Y.; Luo, Y.; Yin, X.; Que, W. The effect of in situ nitrogen doping on the oxygen evolution reaction of Mxenes. Nanoscale Adv. 2020, 2, 1187-1194. [CrossRef]

169. Liang, J.; Zhou, R.F.; Chen, X.M.; Tang, Y.H.; Qiao, S.Z. Fe-N Decorated Hybrids of CNTs Grown on Hierarchically Porous Carbon for High-Performance Oxygen Reduction. Adv. Mater. 2014, 26, 6074-6079. [CrossRef]

170. Wang, Y.C.; Lai, Y.J.; Song, L.; Zhou, Z.Y.; Liu, J.G.; Wang, Q.; Yang, X.D.; Chen, C.; Shi, W.; Zheng, Y.P.; et al. S-Doping of an Fe/N/C Orr Catalyst for Polymer Electrolyte Membrane Fuel Cells with High Power Density. Angew. Chem. Int. Ed. 2015, 54, 9907-9910. [CrossRef]

171. Deng, Y.; Dong, Y.; Wang, G.; Sun, K.; Shi, X.; Zheng, L.; Li, X.; Liao, S. Well-Defined ZIF-Derived Fe-N Codoped Carbon Nanoframes as Efficient Oxygen Reduction Catalysts. ACS Appl. Mater. Interfaces 2017, 9, 9699-9709. [CrossRef]

172. Li, Q.; Chen, W.; Xiao, H.; Gong, Y.; Li, Z.; Zheng, L.; Zheng, X.; Yan, W.; Cheong, W.C.; Shen, R.; et al. Fe Isolated Single Atoms on S. N CodopedCarbon by Copolymer Pyrolysis Strategy for Highly Efficient Oxygen Reduction Reaction. Adv. Mater. 2018, 2, 1800588. [CrossRef]

173. Ma, L.; Chen, S.; Pei, Z.; Huang, Y.; Liang, G.; Mo, F.; Yang, Q.; Su, J.; Gao, Y.; Zapien, J.A.; et al. Single-Site Active Iron-Based Bifunctional Oxygen Catalyst for a Compressible and Rechargeable Zinc-Air Battery. ACS Nano 2018, 12, 1949-1958. [CrossRef] [PubMed]

174. Yuan, K.; Sfaelou, S.; Qiu, M.; Lützenkirchen-Hecht, D.; Zhuang, X.; Chen, Y.; Yuan, C.; Feng, X.; Scherf, U. Synergetic Contribution of Boron and Fe-Nx Species in Porous Carbons toward Efficient Electrocatalysts for Oxygen Reduction Reaction. ACS Energy Lett. 2018, 3, 252-260. [CrossRef]

175. Jiang, L.; Duan, J.; Zhu, J.; Chen, S.; Antonietti, M. Iron Clusters-Directed Synthesis of 2D/2D Fe-N-C/MXene Superlattice Like Heterostructure with Enhanced Oxygen Reduction Electrocatalysis. ACS Nano 2020. [CrossRef] [PubMed]

(C) 2020 by the authors. Licensee MDPI, Basel, Switzerland. This article is an open access article distributed under the terms and conditions of the Creative Commons Attribution (CC BY) license (http://creativecommons.org/licenses/by/4.0/). 